\title{
El acercamiento de la monarquía castellana a la Orden de los Predicadores durante el reinado de Juan II de Castilla (1406-1454) ${ }^{1^{*}}$
}

\author{
The Relationship between the Castilian Monarchy and the \\ Order of Preachers during the Reign of John II of Castile \\ $(1406-1454)^{2}$
}

\author{
Juan Antonio Prieto SAYAguÉs ${ }^{3}$ \\ Universidad de Valladolid \\ juanantonio.prieto@uva.es
}

Recibido: $26 / 10 / 2015$

Aceptado: 14/01/2016

\section{RESUMEN}

Desde la llegada al trono de la dinastía Trastámara los diferentes monarcas castellanos llevaron a cabo una serie de actuaciones respecto a las órdenes religiosas. Durante los primeros años, éstas estuvieron dirigidas, en su mayoría, a la orden franciscana, a lo que habría que sumar la introducción en Castilla de la orden de la Cartuja y las primeras fundaciones jerónimas. Sin embargo, las reinas Beatriz de Portugal y Catalina de Lancaster, junto al infante Fernando de Antequera, fueron los protagonistas del cambio devocional que se produjo en Castilla y que alcanzó su cénit al alcanzar la mayoría de edad Juan II. Desde finales del siglo XIV vieron la luz una serie de fundaciones dominicas y se reformaron algunos conventos por parte de estos personajes; de manera progresiva, comenzaron a confiar en los frailes de esta orden diferentes cometidos espirituales, sociales y políticos.

Palabras clave: Trastámaras, cambio devocional, reformas, Juan II, Orden de los Predicadores.

\begin{abstract}
Following the rise of the Trastámaran dynasty, Castilian kings took several actions concerning religious orders. In the early years, these were mostly directed at the Franciscan Order. In addition, the Carthusian order was established in the kingdom and the first Hieronymite monasteries were founded. Nevertheless, Queens Beatriz of Portugal and Catherine of Lancaster, together with the prince Ferdinand of Antequera,
\end{abstract}

\footnotetext{
${ }^{1}$ El presente trabajo forma parte del Proyecto de Investigación coordinado "Poderes, espacios y escrituras en los reinos occidentales hispánicos (ss. XI-XIV)", ref. HAR2013-42925-P, financiado por el MINECO.

${ }^{2}$ The present study forms part of the coordinated research project "Powers, spaces and writing in the western Hispanic kingdoms (11th to 14th centuries)", ref. HAR2013-42925-P, funded by the Spanish Ministry of Economy and Competitiveness.

${ }^{3}$ Predoctoral researcher in receipt of an FPU grant, in the Department of Ancient and Medieval History at the University of Valladolid.

*I am enormously grateful to Dr. Diana Lucía Gómez-Chacón for her generosity in allowing me access to her unpublished work and for her constant and valuable support.
} 
played a leading role in the devotional change which occurred in Castile and reached its zenith when John II came of age. From the late fourteenth century onwards, they founded several Dominican friaries and gradually began to entrust these monks with spiritual, social and political missions.

Key Words: Trastámaras, Devotional Changes, Reforms, John II, Order of Preachers.

Sumario: 1. Introducción. 2. Antecedentes: los reinados de Enrique II, Juan I y Enrique III (1369-1406). 3. El origen de la devoción dominica en el entorno regio: las reinas Beatriz de Portugal, Catalina de Lancaster y el infante Fernando. 4. El dominicanismo de la monarquía durante la mayoría de edad de Juan II (1418-1454). 4.1. La utilización de los espacios conventuales para usos públicos y privados. 4.2. Los vínculos entre los religiosos y el rey y sus diferentes funciones. 4.3. Los inicios de la reforma de la Orden de los Predicadores (c. 1423-...) y las fundaciones regias. 4.4. El papel intercesor de los dominicos tras la muerte. 5. El nuevo giro devocional: el reinado de Enrique IV. 6. Conclusiones. 7. Bibliografía.

\section{INTRODUCCIÓN}

Durante la Edad Media la monarquía empleó las diferentes órdenes religiosas como un elemento de identidad y memoria. Sin embargo, son escasos los trabajos dedicados a los vínculos entre la monarquía y la Orden de los Predicadores. Para los estadios iniciales del bajomedievo destaca el trabajo de Salustiano Moreta dedicado a Sancho IV y María de Molina ${ }^{4}$ Para épocas más avanzadas, destacan las obras de Nieva Ocampo ${ }^{5}$. No obstante, otros muchos trabajos dedicados a las relaciones entre la Iglesia y la Monarquía castellana dejan entrever dichos vínculos. Entre ellos, cabe mencionar los trabajos de Nieto Soria centrados en dichas relaciones ${ }^{6}$; la obra de Villarroel González focalizada en los vínculos entre la jerarquía eclesiástica secular y el monarca durante el reinado de Juan $\mathrm{II}^{7}$ o, la de Nogales Rincón, dedicada a la Capilla Real $^{8}$. Finalmente, resulta de gran interés la Tesis Doctoral de Lucía Gómez-Chacón acerca del convento dominico de Santa María la Real de Nieva, en la que dedica un capítulo entero a analizar el contexto y las relaciones entre dicha orden y su reforma con la monarquía Trastámara 9 .

Mientras que durante los primeros reinados de dicha dinastía la monarquía protagonizó varias intervenciones de interés respecto a las distintas órdenes religiosas, principalmente la franciscana, cartuja y jerónima, con la llegada al trono de Juan II se produjo una inflexión de la política monástica regia en favor de la Orden de los Predicadores.

Se analizan los orígenes del giro devocional de la monarquía castellana y los vínculos establecidos en con la Orden de los Predicadores en sus diferentes esferas. Partiendo de los últimos años del siglo XIV, nos centraremos en los dos grandes periodos

4 Moreta Velayos, "Notas sobre el franciscanismo y el dominicanismo”, pp. 171-184.

5 Nieva Ocampo, "Los dominicos en Castilla", pp. 13-48; Nieva Ocampo, "Reformatio in membris", pp. 297-341; NiEva OCAMPO, "Dejarlo todo por Dios, es comprar el cielo” pp. 483-512.

${ }^{6}$ Nieto Soria, Iglesia y génesis.

7 Villarroel GonzÁLez, El rey y la Iglesia castellana.

${ }^{8}$ Nogales Rincón, La representación religiosa de la monarquía castellano-leonesa.

${ }^{9}$ Lucía Gómez-Chacón, El monasterio de Santa María la Real de Nieva. 
del reinado de Juan II: la regencia de Catalina de Lancaster y el infante Fernando y los años que siguen a la mayoría de edad del monarca y el comienzo de su reinado efectivo.

\section{ANTECEDENTES: LOS REINADOS DE ENRIQUE II, JUAN I Y ENRIQUE III (1369-1406)}

Los primeros Trastámara emplearon la política de renovación monástica como una vía de legitimación ante su convulso ascenso al trono; Enrique II prestó especial atención a la orden franciscana en contraposición a las escasas noticias que vinculan a la monarquía con la Orden de los Predicadores durante estos años ${ }^{10}$ : apoyó la campaña de visita y corrección de Gregorio XI a los conventos de las provincias franciscanas de Castilla y Santiago durante 1374 y 1375 que terminaron con la deposición del provincial castellano, fray Juan Díaz de Haro, por negarse a la misma ${ }^{11}$. También se hizo cargo de los traslados de las clarisas de Valladolid ${ }^{12}$, Reinoso ${ }^{13}$ y Alcocer ${ }^{14}$ por la situación en que estos cenobios quedaron tras el fin de la contienda bélica. Su hijo y sucesor, Juan I, destacó por su preocupación en la política religiosa del reino: entregó el priorato seglar de Guadalupe a los jerónimos ${ }^{15}$, introdujo a la orden de la Cartuja en Castilla con la fundación de El Paular ${ }^{16} \mathrm{y}$ revitalizó el benedictismo con la fundación de un monasterio urbano de clausura en Valladolid ${ }^{17}$; también promovió a su confesor mayor y embajador, fray Fernando de Illescas como visitador de la naciente

${ }^{10}$ Sin embargo, tras su ascenso al trono, Enrique II escogió confesor de la orden dominica abandonando a su confesor franciscano Diego López de Ribadeneyra y también se sepultó con el hábito de la misma orden. Estas decisiones fueron tomadas con la idea "de adoptar manifestaciones externas de raíz devocional tradicionales de la monarquía castellana", concretamente, continuar la política devocional de Alfonso XI para dar una continuidad legitimista que entroncara con dicho monarca, en Nogales Rincón, La representación religiosa de la monarquía castellano-leonesa, pp. 62 y 213.

${ }^{11}$ Rojo Alique, "El convento de San Francisco de Valladolid (I)", p. 248; AbAd Pérez, "Los ministros provinciales", pp. 340-341.

${ }^{12}$ Las clarisas vallisoletanas se trasladaron durante la guerra civil castellana asentándose en los palacios del infante don Sancho - donados en 1362 -, bajo el patrocinio de la reina Juana Manuel y Enrique II, en CAvero Domínguez, "Monarquía y nobleza”, p. 266; García Oro, Francisco de Asís, p. 296.

${ }^{13}$ Durante la contienda bélica el monasterio de Reinoso de Cerrato quedó muy maltrecho y Enrique II y su esposa, Juana Manuel, fueron los promotores de su traslado a Palencia, en Martín Prieto, "Sobre la promoción regia de la orden franciscana", pp. 65-66; CASTRO y CASTRO, El Real Monasterio de Santa Clara de Palencia, II, no 1 y 2; BeCEIro PItA, "La nobleza y las órdenes mendicantes en Castilla”, p. 321.

${ }^{14} \mathrm{La}$ decadencia material del monasterio se agravó en la segunda mitad del siglo XIV, de nuevo, ante las violencias de la guerra civil entre Pedro I y Enrique II. Con la llegada de la dinastía Trastámara se produjo su traslado al interior de la villa, en Villalba Rú́z de Toledo, "El monasterio de Santa Clara de Alcocer", pp. 320-321; MARTín Prieto, "Formación y evolución del patrimonio", p. 585.

${ }^{15}$ Revuelta Somalo, Los jerónimos, p. 183; Cerro Herranz, Documentación del monasterio de Guadalupe, no 160; Llopis Agelán, "Milagros, demandas y prosperidad”, pp. 421-427.

${ }^{16}$ Cantera Montenegro, "Las relaciones de las cartujas de la Provincia de Castilla", p. 277; LóPeZ DE Ayala, Crónicas, p. 694.

${ }_{17}$ Real Academia de la Historia (en adelante RAH), Salazar y Castro, N-25, fo 304 a 308; Colombás Y Gost, Escritos sobre el primer siglo, pp. 22-30; Olivera Serrano, "Devociones regias y proyectos políticos", p. 801 . 
congregación de clarisas con centro en Tordesillas ${ }^{18}$. Sin embargo, este monarca tampoco tuvo ninguna intervención de interés respecto a la Orden de los Predicadores ${ }^{19}$, si exceptuamos su intento frustrado de fundar un convento de la orden en Medina del Campo - debido a la inesperada muerte del monarca - que llevó a buen término su hijo, el infante Fernando, como señalaremos posteriormente ${ }^{20}$. Enrique III mantuvo como confesor a fray Fernando de Illescas ${ }^{21}$ y otros franciscanos como fray Alfonso de Alcocer, encargando a su hijo que mantuviera a este último en el cargo cuando fuera rey $^{22}$; también tuvo como consejero a fray Juan Enríquez, hijo del adelantado Alfonso Enríquez, quien llegó a ocupar el provincialato franciscano de Castilla entre 1406 y 1409 y después fue obispo de Lugo hasta su muerte en $1418^{23}$. Este monarca también se sepultó con el hábito franciscano en la catedral de Toledo ${ }^{24}$.

Por tanto, durante los primeros reinados Trastámara, la devoción por los dominicos, presentes desde las primeras fundaciones de la orden hasta el reinado de Alfonso XI, cayó hasta sus niveles más bajos. Por el contrario, estos primeros monarcas de la nueva dinastía favorecieron a las nuevas órdenes, quizás con la intención de dotarse de un programa devocional propio y diferente a los reyes precedentes, principalmente, el del malogrado Pedro I.

${ }^{18}$ Castro Toledo, Colección diplomática de Tordesillas, nº 205; Martínez Ruíz, "El monasterio de Santa Clara de Tordesillas", pp. 1879-1894; PAzzis Pi Corrales, "Santa Clara de Villafrechós", p. 1880.

${ }^{19}$ La reforma dominica se extendió por estos años en lugares afines al papa de Roma. Fue Bonifacio IX (1389-1404) quien aprobó el decreto de reforma el 9 de enero de 1391 dando vía libre al maestro general de la obediencia romana, Raimundo de Capua. Dicha reforma fue ajena a los conventos de la obediencia de Aviñón, entre los que se encontraban los cenobios castellanos, a cuyo papa, Clemente VII había reconocido la obediencia oficial Juan I de Castilla en mayo de 1381, en Lucía GómeZ-Chacón, El monasterio de Santa María la Real de Nieva, pp. 111 y 117 y SuÁrez Fernández, Historia del reinado de Juan I de Castilla, $\mathrm{n}^{\circ} 246$. Es significativo que por estos mismos años el rey de Portugal, Juan I de Avís, enemigo del castellano, se produjeran tres importantes fundaciones dominicas en suelo luso: fray Vicente de Lisboa, confesor del monarca portugués y provincial de la Provincia de España, intervino en la fundación del convento observante de monjas dominicas de San Salvador de Lisboa en 1391 y fundó otro de frailes, el de Santo Domingo de Bemfica, en 1399, dándole el rey las casas; Por su parte, Juan I de Portugal fundó en 1394 el monasterio de Batalla. Los dos primeros conventos fueron reformados desde sus respectivas fundaciones, durante el generalato de Tomás Paccaroni de Fermo, en HeRnÁndEz, "La reforma dominicana entre los concilios de Constanza y Basilea", p. 13; Lucía Gómez-Chacón, El monasterio de Santa María la Real de Nieva, pp. 112-113.

${ }^{20}$ Lucía Gómez-Chacón, El monasterio de Santa María la Real de Nieva, pp. 145-146.

${ }^{21}$ García Oro, Los franciscanos en España, p. 78; RodríGuez GuILLÉn, El monasterio de Santa María la Real de Tordesillas, pp. 68-69.

22 "Por quanto yo he tenido diversos confesores de la orden de San Francisco mando y ordeno que frey Alfonso de Alcocer que es agora mi confesor sea confesor del dicho principe mi fijo desque Dios quiera que sea rey", en RAH, Salazar y Castro, O-19, f 126 a. a $126 \mathrm{f}$.

${ }^{23}$ RUCQUOI, "Los franciscanos en el reino de Castilla", p. 75; VV. AA., Diccionario de Historia Eclesiástica de España, 1, p. 600; GARCÍA Oro, Los franciscanos en España, p. 78; Díaz Ibáñez, "Iglesia, nobleza y oligarquías urbanas", p. 206. Este fraile fue uno de los testamentarios de Enrique III junto al franciscano fray Fernando de Illescas, en Galíndez de Carvajal, Crónica del señor rey don Juan Segundo, p. 7.

${ }^{24}$ Salazar y Castro, Historia genealógica de la Casa de Lara, I, p. 349; Arco y Garay, Sepulcros de la Casa Real de Castilla, p. 327. 


\section{EL ORIGEN DE LA DEVOCIÓN DOMINICA EN EL ENTORNO REGIO: LAS REINAS BEATRIZ DE PORTUGAL, CATALINA DE LANCASTER Y EL INFANTE FERNANDO}

Sería la reina Catalina de Lancaster, esposa de Enrique III y el hermano de este último, el infante Fernando, quienes durante el reinado de este monarca llevarían a cabo varias intervenciones de interés respecto a la orden dominica, pese al franciscanismo de Enrique III. Las fundaciones que llevaron a cabo estos dos personajes - además de las jerónimas apoyadas por el infante - fueron dominicas, las primeras de esta orden protagonizadas por el entorno regio en muchos años. Algunas de ellas vieron la luz en villas y lugares de sus respectivos señoríos.

El infante Fernando fundó el convento de San Andrés de Medina del Campo (1390) en nombre de su padre, Juan $\mathrm{I}^{25}$, entregando una iglesia parroquial a la Orden de los Predicadores ${ }^{26}$. El infante también fundó el convento de Santo Domingo en Villalón (1401-1402), para lo cual empleó la fortaleza y alcázar que tenía en la villa; al parecer una de las razones que motivaron al infante a proceder a la fundación fue la existencia de un gran número de judíos en la villa ${ }^{27}$. En 1416, Fernando de Antequera sepultó en el altar mayor de la iglesia conventual a su hijo, el infante Sancho, maestre niño de la Orden de Calatrava, con el deseo de establecer un panteón familiar ${ }^{28}$. Asimismo, el infante Fernando intercedió ante el papa para la consecución de privilegios para la orden, como nos informa un documento de 1442 en que constan las indulgencias concedidas a la Orden de los Predicadores. En dicho texto se afirma que fue el infante quien solicitó a Benedicto XIII la indulgencia de ocho años y cuarenta cuarentenas de perdón a todos los que fueren a visitar el convento de Santo Domingo de Caleruega en la festividad del santo titular ${ }^{29}$. Finalmente, la esposa de Fernando de Antequera, Leonor de Alburquerque, convirtió a los premostratenses de Santa María de los Huertos de Medina del Campo en monasterio de monjas dominicas $(1418)^{30}$ y su hermanastra del mismo nombre profesó tras enviudar en el convento de Sancti Spiritus de Toro, donde años después alcanzó el abadiato ${ }^{31}$.

25 Nieva OCAMPo, "Los dominicos en Castilla", p. 39.

26 Según consta en un documento expedido por Fernando de Antequera y fechado el 22 de noviembre de 1406 "tove por bien de le fazer e fundar a servicio de Dios en la su iglesia que era parrochial de la mi villa de Medina del Campo un monasterio de la orden de los frayles predicadores de Santo Domingo porque la dicha iglesia mejor servida y honrada fuese", en López, Tercera parte de la historia general de Sancto Domingo, pp. 354-355.

27 Nieva OcAmpo, "Los dominicos en Castilla", p. 39.

28 Salazar y Castro, Historia genealógica de la Casa de Lara, III, p. 234.

29 Archivo Histórico Nacional (en adelante AHN), Clero secular-regular, Pergaminos, Carp. 1.964, nº 3.

30 BACKMUND, "La Orden premostratense en España", p. 79. En este monasterio se refugió varias veces Leonor de Alburquerque, como en 1420 "e todavía los tratos andaban entre estos señores, aunque cautelosos como a la fin paresció, e acordóse que el rey se partiese de Ávila para Talavera, lo qual no se hizo saber a la reyna de Aragón, que estaba en Fontiveros esperando el fin destos tratos, la qual se tuvo desto por muy injuriada, e partióse de Fontiveros, e fuese a Medina del Campo, donde ella hacia su morada en un monesterio que ende labró", en Galíndez de CARvajal, Crónica del señor rey don Juan Segundo, p. 173.

31 La devoción de la reina de Aragón hacia la Orden de los Predicadores queda de manifiesto en una donación que realizó a su hermanastra el 21 de junio de 1418 “considerando esso mismo el gran debdo de sangre, que vos Doña Leonor nuestra hermana, priora del monasterio de Sancti Spiritus de Toro, avedes con Nos, e como servicio de Dios escogistes ser apartada en Religión. E otrosi, porque avemos sido certificada de 
El dominicanismo de la reina Catalina Lancaster también fue claro. Continuando la devoción de su antecesora, la reina Beatriz de Portugal - quien, tras la muerte de su marido, el rey Juan I de Castilla, se retiró al convento de Sancti Spiritus de Toro, donde también se sepultós ${ }^{32}$-, la esposa de Enrique III fundó los conventos de San Pedro Mártir de Mayorga ${ }^{33}$ y Santa María de Nieva ${ }^{34}$. Tras la fundación del segundo de ellos se pueden apreciar connotaciones políticas y jurisdiccionales, que gravitaron en torno a la imagen de la Virgen hallada, origen del levantamiento del convento. La imagen era reclamada tanto por la nobleza segoviana, quien pedía que debía de hallarse en la catedral, como por el párroco de Nieva, quien reclamaba sus derechos sobre el lugar dónde fue hallada ${ }^{35}$. La reina estaba influida por fray Vicente Ferrer y consejeros y confesores pertenecientes a esta orden como fray Álvaro de Córdoba, hermano de su cortesana, Leonor López de Córdoba; fray Juan de Morales, después obispo de Badajoz y Jaén ${ }^{36}$ y fray García, profeso de San Ildefonso de Toro y posteriormente obispo de Coria, canciller mayor del infante Enrique y maestre de Alcántara ${ }^{37}$. Como señala Nogales Rincón, la sustitución que en 1410 hizo Catalina de Lancaster del franciscano fray Alfonso de Alcocer por un dominico como confesor de Juan II podría ser un síntoma más de las preferencias devocionales de la reina a favor de esta última orden ${ }^{38}$.

Las relaciones de la reina madre con los dominicos se pueden apreciar a través de otra serie de hechos. Catalina de Lancaster, como nieta del monarca asesinado en Montiel, siempre mantuvo unas buenas relaciones con los familiares del último

vuestra buena contemplativa vida, e como avedes tenido, e tenedes continuas oraciones, por las anima de los reyes, e reyna donde nos venimos [...] Nos la Reyna doña Leonor, condesa de Alburquerque [...] otorgamos [...] a vos la dicha doña Leonor, nuestra hermana, priora del dicho monasterio de Sancti Spiritus de Toro, diez mil maravedís". Además de esta cuantía, el cenobio toresano recibió otras mercedes por parte de la familia real durante estos años: en 1411, durante la regencia de Juan II, éste le entregó 8.000 maravedís y, en 1424, la Corona le hizo donación de otros 18.000 maravedís, en Lucía GómEz-CHACón, "Religiosidad femenina y reforma dominicana", (en prensa).

32 Yarza Luaces, La nobleza ante el rey,p. 181; Pérez Vidal, "Sancti Spiritus de Toro", p. 12; La elección de este cenobio como lugar de descanso eterno por la reina Beatriz pudo deberse a la atracción sentida por los orígenes lusos de la fundadora del convento, Teresa Gil, amante de Sancho IV, en Lucía Gómez-CHACóN, "Religiosidad femenina y reforma dominicana", (en prensa). Además, la reina Beatriz de Portugal tuvo otras intervenciones significativas hacia conventos dominicos que tendrían una intensa relación con la monarquía durante el siguiente reinado, destacando la cesión que hizo en 1398 a San Pablo de Valladolid de todo el solar que tenía junto al convento, desde la cerca de la puerta del patio hasta el postigo que llamaban de San Pablo, en Palomares IbáÑez, “Aspectos de la historia del convento de San Pablo de Valladolid”, p. 102.

33 Nieva OCAMPo, "Reformatio in membris”, p. 331; Echevarría Arsuaga, Catalina de Lancaster, p. 80.

${ }^{34}$ Colmenares, Historia de la insigne ciudad de Segovia, pp. 538-539; Echevarría Arsuaga, Catalina de Lancaster, p. 80. Catalina de Lancaster patrocinó las obras de ampliación de la iglesia comenzadas en 1414 y pasó largas temporadas en las estancias regias del piso superior, en Lucía Gómez-Chacón, "Reinas y Predicadores: el Monasterio de Santa María la Real de Nieva", p. 327; CABALlero EscAmilla, "Palacios y conventos a finales de la Edad Media", pp. 271-273.

35 Lucía Gómez-Chacón, Apariciones marianas y renovación monástica en la Castilla bajomedieval, $\mathrm{p}$. 223.

${ }^{36}$ Nieto Soria, Iglesia y génesis, pp. 144-145.

37 López, Tercera parte de la historia general de Sancto Domingo, p. 306.

38 Nogales Rincón, “Confesar al rey en la Castilla bajomedieval”, p. 66. El provincial dominico fue uno de los testamentarios de la reina, lo que indica los contactos entre la misma y las autoridades de la orden en Echevarría Arsuaga, Catalina de Lancaster, p. 199. 
monarca de la dinastía borgoñona, muchos de los cuales habían escogido la carrera religiosa como forma de promoción una vez que cayeron en desgracia. Tuvo una especial relación con quien fuera amante de Pedro I, Teresa de Ayala, y la hija habida entre ambos, María de Castilla - tía de la reina Catalina -, quienes entraron profesas en el monasterio de Santo Domingo el Real de Toledo. En 1396 daba un privilegio por el que concedía a la segunda de ellas, priora del mismo, una merced de 16.500 maravedíes vitalicios situados en las rentas de la villa de Huete ${ }^{39} \mathrm{y}$, un poco después, a comienzos de 1397 concedió a su madre, Teresa de Ayala, 4.000 maravedíes de juro de heredad situados en las escribanías de la villa de Huete y su tierra ${ }^{40}$. A cambio de esta protección y trato, la reina Catalina pidió varios favores a lo largo de su vida a sus tías profesas en el convento toledano, como en 1417 que acogieran tras sus muros a su segunda valida, Inés de Torres, cuando tuvo que dejar la Corte en uno de sus momentos más bajos ${ }^{41}$, debido al escándalo que despertaron sus relaciones con el señor de Villalobos, Juan Álvarez de Osorio ${ }^{42}$. Igualmente, la reina confió a este monasterio la custodia de sus tesoros, como reconoce el 2 de marzo de 1403 su antiguo camarero, Francisco Fernández, quien afirmaba haber recibido de la priora Teresa de Ayala y de la monja Francisca Alfonso, "cuanto yo dexe en guarda algunas veces a vos doña Françisca Alfonso e a otras personas del dicho monesterio pieças de cosas de la camara de la dicha señora reyna"43. La reina también escribió varias cartas entre 1407 y 1408 a Teresa de Ayala informándole del mal estado de salud de la infanta Catalina y rogándole que se hicieran rogativas y procesiones para su pronta recuperación ${ }^{44}$.

Catalina de Lancaster también tuvo relaciones con la orden en el aspecto funerario. En 1410 ordenó que el infante don Sancho, su tío, fuese enterrado en el cenobio de monjas dominicas de Toledo ${ }^{45}$ al igual que el infante Diego, hijo de Pedro I, quien fue enterrado al lado de Juana de la Espina cuando se trasladó el 28 de diciembre de 1448, posiblemente por orden de su hija Catalina de Castilla, por entonces priora del monasterio ${ }^{46}$. Otra fuente dice que ambos infantes yacen en la misma sepultura a la que habrían sido trasladados en esta última fecha ${ }^{47}$. Catalina de Lancaster eligió el hábito dominico como forma de ingreso póstumo en la orden, como aparece representada en su sepulcro ${ }^{48}$. Pese a enterrarse en la Capilla de Reyes Nuevos de Toledo, el cuerpo de la reina fue puesto en depósito en el monasterio de Santa María la Real

\footnotetext{
${ }^{39}$ CAÑas Gálvez, Colección diplomática de Santo Domingo el Real de Toledo, $\mathrm{n}^{\circ} 50$.

${ }^{40}$ Ibidem, $\mathrm{n}^{\circ} 51$.

${ }^{41}$ Echevarría Arsuaga, Catalina de Lancaster, pp. 137-138; CaÑas Gálvez, Colección diplomática de Santo Domingo el Real de Toledo, $\mathrm{n}^{\circ} 112$.

42 Beceiro Pita, "La nobleza y las órdenes mendicantes en Castilla", p. 343; Galíndez de Carvajal, Crónica del señor rey don Juan Segundo, pp. 151-152.

${ }^{43}$ CAÑas Gálvez, Colección diplomática de Santo Domingo el Real de Toledo, $\mathrm{n}^{\circ} 64$.

${ }^{44}$ Ibidem, $\mathrm{n}^{\mathrm{O}} 83$.

${ }^{45}$ Nieva Ocampo, "Los dominicos en Castilla", p. 34; Castillo, Segunda parte de la Historia General de Santo Domingo, p. 100 r.; CAÑas Gálvez, Colección diplomática de Santo Domingo el Real de Toledo, $\mathrm{n}^{\circ}$ 95; Echevarría Arsuaga, Catalina de Lancaster, pp. 136-137.

${ }^{46}$ Echevarría Arsuaga, Catalina de Lancaster, p. 137.

${ }^{47}$ Sitges, Las mujeres del rey don Pedro de Castilla, p. 452.

${ }^{48}$ Caballero Escamilla, "Palacios y conventos a finales de la Edad Media", p. 269. Esto le diferenciaría de la reina Juana Manuel, quien lo hizo en el hábito franciscano, en Nogales Rincón, La representación religiosa de la monarquía castellano-leonesa, p. 1635.
} 
de Nieva desde su fallecimiento el 2 de junio de 1418 hasta el 10 de diciembre de 1419 en que fue trasladado a la catedral toledana ${ }^{49}$. También acordó en su testamento que su hijo, el rey Juan II, cumpliera las capellanías de los conventos dominicos de Santo Domingo el Real de Toledo y Santa María la Real de Nieva ${ }^{50}$.

Por tanto, intuimos que en el cambio devocional al que asistió la monarquía castellana durante la primera mitad del siglo XV, tuvo mucho que ver la influencia de las reinas Trastámara. La primera de ellas, Juana Manuel, era descendiente del linaje que más protegió a la orden durante el siglo XIV e incluso recibió encargos de continuar beneficiando las fundaciones familiares ${ }^{51}$; la segunda esposa de Juan I de Castilla, la reina Beatriz de Portugal, se sepultó en el convento de monjas dominicas de Sancti Spiritus de Toro, como hemos señalado, y a falta de su testamento, no poseemos muchos más datos que la vinculen a la Orden de los Predicadores; finalmente, la reina Catalina, culminó tal labor como acabamos de señalar, comenzando el verdadero repunte de una orden, tradicionalmente vinculada a la monarquía y olvidada por ella durante los primeros reinados Trastámara ${ }^{52}$. Su sucesora, María de Aragón, no se destacó por su especial devoción a la Orden de los Predicadores como ponen de manifiesto sus fundaciones religiosas. Sin embargo, tuvo algunas intervenciones de interés respecto a la orden en las que se aprecian su interés continuista con sus precedentes: en su testamento renunció 2.000 maravedís de juro de heredad en Santa María de las Dueñas de Medina del Campo ${ }^{53}$, sus restos fueron llevados a Santa María la Real de Nieva donde permanecieron en depósito hasta su traslado definitivo al monasterio de Guadalupe, y en su testamento expresaba sus deseos de sepultarse con el hábito dominico ${ }^{54}$.

${ }^{49}$ Lucía Gómez-Chacón, El monasterio de Santa María la Real de Nieva, p. 196.

${ }^{50}$ Echevarría Arsuaga, Catalina de Lancaster, p. 200.

${ }^{51}$ Cabe recordar que el padre de la reina, el infante don Juan Manuel, fundó el convento de San Juan y San Pablo de Peñafiel en 1318, contribuyó a la fundación de las dominicas de Belmonte e intentó fundar otro cenobio dominico en Alarco pero no recibió la bula papal, en 1335. AHN, Clero secular-regular, Códices, L. 1264, f. 397; Castillo, Segunda parte de la Historia General de Santo Domingo, pp. 68v-69r.; Ayllón GuTIÉRREZ, Iglesia rural y sociedad en la Edad Media, pp. 287 y 296. Igualmente significativo resulta el hecho de que en mayo de 1419 la priora de la fundación dominica de Leonor de Alburquerque, el convento de Santa María de las Dueñas de Medina del Campo, fuera Aldonza Manuel, en AHN, Clero secular-regular, Legajo 7.562, doc. 3 .

${ }^{52}$ Entre los legajos relativos al convento de San Juan y San Pablo de Peñafiel albergados en el AHN se encuentra un documento que pone en valor lo señalado. Se trata de la recopilación de cartas expedidas por los reyes, reinas e infantes de Castilla a favor de dicho cenobio. De las mismas, 9 de ellas fueron expedidas por la reina Juana Manuel, 3 por la reina Beatriz de Portugal y ninguna por sus respectivos maridos, Enrique II y Juan I. De Enrique III aparece un documento, 5 del infante Fernando, 8 de Juan II y solamente 2 se deben a Enrique IV cuando todavía era príncipe heredero, en AHN, Clero secular-regular, Legajo 7.635.

${ }_{53}$ Como señala la Dra. Diana Pelaz Flores, no se hace extraño que María de Aragón apoyara económicamente este cenobio, fundación de su madre, Leonor de Alburquerque, ya que estaba "intrínsecamente vinculado a su memoria familiar". Sin embargo, más allá de intervenciones puntuales en algunos conventos dominicos, la devoción de esta reina se orientó más hacia otras órdenes como los jerónimos y cartujos, en Pelaz Florez, “Reynante(s) en vno”, pp. 243 y 249-256 y Lucía Gómez-Chacón, Apariciones marianas y renovación monástica en la Castilla bajomedieval, pp. 236 y 237.

${ }^{54}$ Lucía Gómez-Chacón, El monasterio de Santa María la Real de Nieva, p. 189. 


\section{EL DOMINICANISMO DE LA MONARQUÍA DURANTE LA MAYORÍA DE EDAD DE JUAN II (1418-1454)}

Las bases ya estaban puestas y cuando Juan II alcanzó la mayoría de edad continuó con la política comenzada por los regentes. Por primera vez desde el ascenso Trastámara la monarquía se vinculaba claramente a una orden religiosa por encima de las otras, al igual que era la primera vez que un monarca aunaba en su persona las dos líneas dinásticas, la Trastámara y la de Borgoña, esta última por parte de su madre.

\subsection{LA UTILIZACIÓN DE LOS ESPACIOS CONVENTUALES PARA USOS PÚBLICOS Y PRIVADOS}

Por lo que respecta al espacio material de los conventos, cabe señalar que el nuevo rey había nacido en el convento dominico de San Ildefonso de Toro ${ }^{55}$, lo que motivó a Enrique III a concederle un privilegio, como se conoce por la confirmación del propio Juan II:

por la qual me ficieron relacion en como el rey don Enrique, mi padre e mi señor, que aya santo paraiso, les fizo mercet e limosna de 4.000 maravedis en cada año, por enmienda de algunos dapnos que avian rescevido estando en el dicho monesterio la reyna mi señora e mi madre, que aya Santo Parayso, quando estava encinta de mi; e eso mesmo por el mi nascimiento, que nasci en el dicho monesterio, e porque fuesen tenidos de rogar a Dios por sus animas e por la mi vida e salut ${ }^{56}$.

El monarca también aprovechó su efeméride, festividad de Santo Tomás de Aquino, para convertirla en una clara exaltación del poder regio estableciendo ese día ceremonias y procesiones anuales en los conventos dominicos de varias ciudades como Toro, Tordesillas, Toledo o Murcia ${ }^{57}$. Sirva como ejemplo, la carta enviada el 19 de abril de 1427 por la reina María de Aragón, primera esposa de Juan II, al provincial de la orden disponiendo que pese a sus protestas, los frailes de San Pedro Mártir acudieran todos los años a Santo Domingo el Real de Toledo a celebrar la festividad de Santo Tomás de Aquino ${ }^{58}$. El hecho de que la procesión tuviera lugar en el convento

55 Cañas Gálvez, El itinerario de la corte de Juan II, pp. 163-164; ArCo y Garay, Sepulcros de la Casa Real de Castilla, p. 271; VV. AA., Diccionario de Historia Eclesiástica de España, 4, p. 2774; López, Tercera parte de la historia general de Sancto Domingo, p. 303; Sánchez Domingo, Privilegios reales de la cartuja de Miraflores, p. 117; Galíndez de CARvajal, Crónica del señor rey don Juan Segundo, p. 7.

56 Floranes y Encinas, Memorias para la historia de la ciudad y tierra de Toro, p. 51.

57 Ibidem, p. 52; Ayllón Gutiérrez, La Orden de los Predicadores en el sureste de Castilla, p. 51.

${ }^{58}$ Lo que realmente estaba en juego era si las monjas tenían que guardar obediencia a su propio prior o al prior dominico de San Pedro Mártir. De hecho, en esta carta la reina también solicitaba al provincial de la orden que mantuviera como prior de Santo Domingo el Real de Toledo a fray Juan de Simancas, argumentando la reina que "es buena persona e non fase gasto a la orden", en CAÑAs GálvEZ, Colección diplomática de Santo Domingo el Real de Toledo, n 175; CAÑAs GÁLvez, "Urraca Téllez: Ascendencia social y proyección políticoreligiosa de una priora", pp. 299-300. El prior fray Juan de Simancas, era una persona muy cercana a la Corte y más concretamente a las reinas, como demuestra el hecho de que después de ser priores de Santo Domingo el Real de Toledo, tanto fray Juan de Simancas como fray Juan de Caldefrancos, alcanzaran el priorazgo de Santa María la Real de Nieva, convento cuyo patronazgo correspondía a las reinas, en LuCía GómEZ-CHACóN, "Reinas y Predicadores: el Monasterio de Santa María la Real de Nieva", pp. 338-339. 
femenino desató las iras de los dominicos de San Pedro Mártir. El monarca tuvo que intervenir el 20 de enero de 1429 ordenando a los frailes dominicos que acudieran a Santo Domingo el Real de Toledo a celebrar dicha fiesta:

fago vos saber que por quanto en el dia del doctor Santo Tomás de Quino se fase e celebra de cada año la fiesta e solepnidat del mi nasçimiento en el monesterio de Santo Domingo el Real desa dicha çibdat de Toledo, que my merçed e voluntad es que esa dicha çibdat vayades onrar la dicha fiesta al dicho monesterio de cada año porque entiendo que asi cunple a serviçio de Dios e my ${ }^{59}$.

A lo largo de su vida el monarca también se hospedó en algunos cenobios de la orden como el femenino de Santa María la Real de Medina del Campo, donde estuvieron alojados Juan II, la reina María y el príncipe Enrique durante los primeros días de junio de 1441, siendo asentado en sus proximidades el campamento real castellano durante los días previos al asalto de Medina del Campo por los infantes de Aragón ${ }^{60}$; igual hizo en San Pablo de Palencia, donde se encontraba el rey el 25 de julio de 1425 cuando varios nobles firmaban una carta de confederación a favor de Álvaro de Luna $^{61}$. Sin embargo, tuvo una especial predilección hacia el cenobio vallisoletano, donde no sólo fue educado por su comunidad de religiosos, sino que también se alojó en innumerables ocasiones a lo largo de su vida. Su madre, la reina Catalina, ordenó la construcción de otro palacio en la huerta conventual por su mal estado, que fue devuelto a los dominicos en 1467 y transformado en viviendas de alquiler ${ }^{62}$. En este último cenobio, además de pasar largas temporadas ${ }^{63}$ también se celebraron importantes ceremonias como el acatamiento del infante don Sancho - hijo de Fernando de Antequera - como maestre de la Orden de Alcántara (1409) ${ }^{64}$, la recepción de los embajadores granadinos $(1409)^{65}$, la jura del príncipe Enrique $(1425)^{66}$, los festejos por

59 CaÑas Gálvez, Colección diplomática de Santo Domingo el Real de Toledo, nº 176.

${ }^{60}$ En 1420 la reina María de Aragón suplicó a su marido, Juan II, "que le diese licencia para ir a Toledo y estar ende en Sancto Domingo el Real quince o veinte días, el qual gela dio, e la reyna se vino a Toledo", en Galíndez de Carvajal, Crónica del señor rey don Juan Segundo, p. 183.

61 CAÑas Gálvez, El itinerario de la corte de Juan II, pp. 152 y 154.

62 Nieva OCAMPo, "Los dominicos en Castilla", p. 35; RucQuoI, "Valladolid a finales del siglo XV. La ermita de Prado", pp. 20 y 27.

${ }^{63}$ Como señaló Palomares Ibáñez, la residencia de Juan II en este convento tuvo matices diferentes a las realizadas en otros cenobios. Además de su larga y continuada duración, no se trató de simples visitas, ni de reposo, sino que en muchas ocasiones llevó una vida en común con los frailes, en PALOMAREs IBáÑez, "Aspectos de la historia del convento de San Pablo de Valladolid", p. 105.

64 Porras Arboledas, Juan II (1406-1454), p. 48.

65 Nieva OcAmpo, "Los dominicos en Castilla”, p. 35; GonzÁlez SÁnchez, Itinerario de don Fernando regente de Castilla, p. 43. Para la recepción, la reina Catalina "fizo adreçar muy bien el refitorio de los frayles, de paños de oro e de sirgo, e de paños de corte muy ricos, e fizo poner vn asentamiento, muy honradamente, con paños de oro, do se asentase el rey. E allí vino el rey, e la reyna su madre e el infante, e allí estavan todos los grandes del reyno, e los prelados e duques e condes e ricos omes e otros cavalleros", en CAÑAS GÁLVEZ, El itinerario de la corte de Juan II, p. 149.

66 Porras Arboledas, Juan II (1406-1454), p. 126; "E mando el rey que todas las cibdades enviasen nuevos poderes para jurar al príncipe don Enrique, e así se hizo. E pasada la fortuna del invierno el rey mandó que se hiciese el juramento en el mes de abril, para lo qual mandó muy ricamente adereszar una gran sala, que es refitorio del monesterio de San Pablo de Valladolid, e allí mando hacer su asentamiento real en la forma que en Toledo se hizo quando fue jurada la infanta doña Catalina, e túvose en ello la mesma forma que en 
la inminente boda de Leonor de Aragón y el rey portugués $(1428)^{67}$, la celebración del enlace entre el príncipe Enrique y Blanca de Navarra $(1440)^{68}$ y la recepción del caballero borgoñón Jacques de Lalaing $(1448)^{69}$. También tenemos constancia de estancias reales en otros cenobios de la orden. Durante las visitas de Juan II a Peñafiel, verificadas en 1421, 1429, 1444, 1446 y 1447, la familia real se debió alojar en la fundación dominica del infante don Juan Manuel, bajo la advocación de San Juan y San Pablo. Durante el sitio puesto por el rey a la villa en junio de 1429, en este convento le fueron entregadas las llaves de la villa y del castillo el día 27 de aquel mismo mes. E1 8 de septiembre, desde aquellas mismas estancias, concedió la villa de Palenzuela con su castillo a Fadrique Enríquez, almirante de Castilla ${ }^{70}$. Igualmente, en Santa María la Real de Nieva ${ }^{71}$ y Santa María de las Dueñas de Medina del Campo ${ }^{72}$ se alojaron en varias ocasiones diferentes miembros de la familia real como la reina y el príncipe don Enrique, donde también se llevaron a cabo acuerdos políticos y ceremonias.

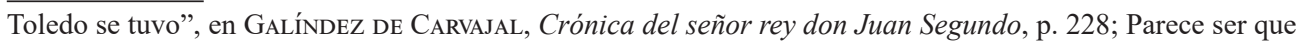
en este mismo cenobio había sido jurado el mismo Juan II, siendo niño, delante de su padre, el rey Enrique III, Villarroel González, El rey y la Iglesia castellana, pp. 178-179.

67 “...Y el rey de Navarra hizo sala al rey e a la reyna e a todos los señores e dueñas que fueron en la fiesta del infante, la qual se hizo en su posada que era en San Pablo, donde había un muy gran corral, en el qual mandó hacer una casa de madera toldada de tapicería, en tal manera que parescía casa muy gentil de aposentamiento, con cámara e salas muy ricamente aireadas: e lo alto de toda la casa era cubierto de piezas de paño morado e amarillo; e la sala principal donde cenaron, era el suelo de céspedes verdes de tal manera juntos, que parescían ser prado natural, y en torno della había poyos hechos de los mesmos céspedes, e al cabo estaba un asentamiento de madera muy grande colgado de muy ricos brocados, donde el rey y el príncipe y las reynas y el infante e las infantas se asentaron, e hubo otros asentamientos muy ricamente aderezados, donde se asentaron las señoras de estado e los caballeros principales que ende estaban: e pasada la danza e la cena, el rey de Navarra mandó hacer la argesa a los oficiales de armas y trompetas", en GALíndeZ DE CARVAJAL, Crónica del señor rey don Juan Segundo, p. 251.

68 "E otro día jueves (15 de septiembre de 1440) vinieron el rey y la reyna de Navarra e todos los otros grandes señores con él a palacio del rey y el rey e la reyna, e todos ellos juntamente fueron adonde la princesa estaba a su cámara con la reyna su madre, e truxéronla a una gran sala que ende estaba muy ricamente toldada, e allí el cardenal de San Pedro les dixo la misa, y los veló [...] E acabada la misa llevaron a la princesa a la cámara de la reyna su suegra e porque el rey se sintía enojado fuese a su cámara, que no quiso comer, pero comieron este día con la reyna y el rey y la reyna de Navarra y el príncipe e la princesa y el almirante e doña Beatriz hija del rey don Dionis, e la boda se hizo quedando la princesa tal qual nació, de que todos ovieron grande enojo y estaba acordado que la princesa saliese a Misa el domingo adelante, e no se hizo, porque en estos días murió el adelantado Pero Manrique, e por esto se dilató la salida hasta viernes siete de Otubre", en Galíndez de CARVAJAL, Crónica del señor rey don Juan Segundo, pp. 410-411.

69 RuCQuOI, Valladolid en la Edad Media, p. 305.

70 CAÑas Gálvez, El itinerario de la corte de Juan II, p. 151.

71 En 1441, tras la petición del rey y del príncipe Enrique, se convocó a las reinas de Castilla y Navarra en este cenobio para "dar forma en algún sosiego a los debates que estaban comenzados"; en este mismo año se celebraron las exequias por la reina Blanca de Navarra, a las que acudieron su marido y el rey castellano; finalmente, a inicios de 1444, el príncipe Enrique estuvo en el cenobio junto al almirante de Castilla y Juan Pacheco, adonde también acudió el rey de Castilla, en Galíndez de CARvajal, Crónica del señor rey don Juan Segundo, pp. 415, 421 y 467.

${ }^{72}$ La reina María de Aragón y su hijo el príncipe Enrique, junto a la reina de Portugal se aposentaron en 1441 en Santa María de las Dueñas de Medina del Campo, en los días anteriores al asalto de dicho lugar por los infantes de Aragón. En este cenobio también se llegaron a acuerdos entre las distintas partes, en CAÑAS GÁlvez, El itinerario de la corte de Juan II, p. 154; GALíndEZ DE CARVAJAL, Crónica del señor rey don Juan Segundo, pp. 433-437. 


\subsection{LOS VÍNCULOS ENTRE LOS RELIGIOSOS Y EL REY Y SUS DIFERENTES FUNCIONES}

Las relaciones con la orden continuaron a través de religiosos y religiosas que estuvieron presentes en varios momentos de la vida del monarca: el propio Juan II había sido educado en San Pablo de Valladolid por su comunidad de religiosos "per plures annos in sua iuventute seu pueritia in dicta domo educatus necnon bonis moribus atque doctrinis instructus fuit"73. Teresa de Ayala y su hija, María de Castilla, las profesas de Santo Domingo el Real de Toledo a las que anteriormente hicimos alusión, tuvieron un papel destacado en el embarazo y parto de Catalina de Lancaster, en el cuidado del recién nacido y futuro Juan $\mathrm{II}^{74} \mathrm{y}$ en el nacimiento de la primera hija de este monarca, la infanta Catalina: el 3 de septiembre de 1422, el rey rogaba a las monjas que acudieran con la reina a Illescas para acompañarla durante su parto, permaneciendo en la Corte hasta el 22 de octubre cuando Juan II les dio la licencia para regresar al convento ${ }^{75}$. Además, a mediados de noviembre de ese mismo año, el rey preparaba la ceremonia de reconocimiento de la infanta Catalina, ayudado por su esposa, quien escribió a la priora Teresa de Ayala para que le informase cómo se había realizado la ceremonia de entrada en Toledo de Catalina de Lancaster y su hija María, unos años atrás ${ }^{76}$. Juan II también tuvo a otros dominicos en su entorno como el consejero, oidor de la Audiencia y canciller mayor y confesor del príncipe Enrique, fray Lope de Barrientos ${ }^{77}$. El monarca lo nombró como uno de sus testamentarios y fue testigo en la redacción del testamento ${ }^{78}$, donde Juan II recomendó a su hijo, el príncipe Enrique

especialmente que tenga cerca de si en el su consejo a los dichos obispo de Cuenca (Lope de Barrientos) e prior don fray Gonzalo de Illescas mis confesores e del mi consejo, que son personas leales e prudentes e provectos, de bueno e sano consejo, e temen a Dios e aman mi servicio e del dicho principe, e la justicia e el bien comun e paz e sosiego de mis regnos, e soy cierto que siempre le daran bueno e sano e verdadero e fiel consejo, con los quales el comunique e aya su deliberacion e acuerdo e consejo en todas $\operatorname{cosas}^{79}$.

${ }^{73}$ Lucía Gómez-Chacón, El monasterio de Santa María la Real de Nieva, p. 173.

${ }^{74}$ Echevarría Arsuaga, Catalina de Lancaster, p. 86; CAÑas Gálvez, Colección diplomática de Santo Domingo el Real de Toledo, $\mathrm{n}^{\circ}$ 67-80.

${ }^{75}$ CaÑas Gálvez, Colección diplomática de Santo Domingo el Real de Toledo, no 151 y 155. "E asimesmo mandó el rey que ende viniesen doña Juana de Mendoza mujer del almirante don Alonso Enríquez, e doña María Monja de Santa Clara, hija del rey don Pedro, e la mujer de Diego Pérez Sarmiento, e doña Elvira Portocarrero mujer de Álvaro de Luna, señor de Santistevan, e doña Teresa de Ayala, priora del monesterio de Santo Domingo el Real de Toledo", en Galíndez de CARvajal, Crónica del señor rey don Juan Segundo, p. 217.

76 Villarroel González, El rey y la Iglesia castellana, pp. 196-197.

77 Martínez Casado, Lope de Barrientos, pp. 29-30; Nieva Ocampo, "Los dominicos en Castilla", p. 33

${ }^{78}$ En su testamento de 8 de julio de 1454, Juan II dio amplias facultades a sus testamentarios fray Lope de Barrientos, fray Gonzalo de Illescas y Juan de Padilla "a los quales apodero por la presente en todo mi tesoro e plata e oro e moneda amonedada e joyas e en todas las otras mis cosas e bienes e do poder e autoridad con libre e conplida facultad a ellos o a la mayor parte dellos [...] para que puedan tomar e tomen del mi tesoro el oro e plata e otras qualesquier cosas que yo tengo en el monesterio de San Benito de Valladolid e en otras qualesquier partes", en RAH, Salazar y Castro, O-19, $\mathrm{f}^{\mathrm{O}} 84 \mathrm{a} 84 \mathrm{~g}$.

${ }^{79} \mathrm{RAH}$, Memorias de Enrique IV, $\mathrm{n}^{\circ} \mathrm{XLVI}$. 
Cuando Juan II entregó el maestrazgo de Santiago a su hijo, el infante don Alfonso, al ser este un niño ordenó que en su lugar tuviera la administración fray Lope de Barrientos y fray Gonzalo de Illescas hasta que el infante cumpliera los 14 años. Asimismo mandó que la reina fuera tutora y administradora de los infantes Alfonso e Isabel y de sus bienes hasta que cumplieran 14 y 12 años respectivamente "e que los rija e administre con acuerdo de consejo de los dichos obispo de Cuenca e por don fray Gonzalo de Illescas mis confesores e del mi consejo que son personas de quien yo mucho fio e tales que siempre le daran bueno e sano consejo"80. La mayor parte de los confesores de Juan II pertenecieron a la Orden de los Predicadores como Álvaro de Córdoba, Juan de Villalón, Alonso de Cusanza, Rodrigo de Valencia, Luis de Valladolid y Juan de Morales ${ }^{81}$; estos dos últimos también fueron sus maestros durante su etapa de infante y Juan de Morales, ya obispo de Badajoz, estuvo presente en la ceremonia de acceso al trono de Juan II en las Cortes de Madrid de $1419^{82}$. Por su parte, Alonso de Cusanza, fue miembro del Consejo Real ${ }^{83}$.

Juan II también aprovechó su ascendencia sobre algunos religiosos para obtener otros servicios políticos. El 29 de septiembre de 1422 el monarca envió una misiva a Teresa de Ayala, priora de las dominicas toledanas, para que persuadiese a doña Mencía, hija de Pedro Carrillo, alguacil mayor del rey en Toledo, para que no tomase hábito de monja y contrajera matrimonio con el señor de Valdecorneja, Fernando Álvarez de Toledo ${ }^{84}$. Años después, el monarca ordenó a fray Lope de Barrientos que arrojase al fuego los escritos de Enrique de Villena, como reconoce el dominico en su obra de las Especias de adevinança, que copiló por mandamiento del monarca: "Este es el libro aquel (uno de magia) que tu, como rey cristianisimo, mandaste a mi tu siervo et fechura, que lo quemase a vueltas de otros muchos"; el lugar escogido para ejecutar la acción fue otro monasterio dominico: Santo Domingo el Real de Madrid ${ }^{85}$. La importancia política de las comunidades dominicas, queda también de manifiesto en la carta enviada por el monarca el 3 de febrero de 1451 a los mayordomos de Santo Domingo el Real de Toledo permitiéndoles circular libremente por Castilla, porque

es necesario de enviar aqui a la my corte e a algunas de las otras çibdades e villas e logares de los dichos mys regnos e señorios e a otras partes a Juan Gonçales Pericon et a Fernando Gonçales de Cuenca e a Pedro de Tapia, sus mayordomos [...] a procurar algunas cosas conplideras a ella e al dicho monesterio, et que se reçelan por causa de los movimientos acaesçidos en la dicha çibdat de Toledo que los dichos [...] sean presos sus cuerpos e tomados sus bienes e fechos otros desaguisados de aqui adelante non

\footnotetext{
${ }^{80}$ RAH, Salazar y Castro, O-19, f 84 a 84 g.

${ }^{81}$ Echevarría Arsuaga, Catalina de Lancaster, pp. 126-130; Martínez Casado, Lope de Barrientos, p. 25; CAÑAs Gálvez, El itinerario de la corte de Juan II, p. 149.

${ }^{82}$ VV. AA., Diccionario de Historia Eclesiástica de España, 1, p. 600; López, Tercera parte de la historia general de Sancto Domingo, Libro Segundo, p. 95; Villarroel González, El rey y la Iglesia castellana, p. 175.

${ }^{83}$ Villarroel González, El rey y la Iglesia castellana, p. 111-113.

${ }^{84}$ Cañas Gálvez, Colección diplomática de Santo Domingo el Real de Toledo, $\mathrm{n}^{\circ} 154$.

85 Villar y Macías, Historia de Salamanca, IV, pp. 74-76; Colmenares, Historia de la insigne ciudad de Segovia, pp. 580 y 584; Layna Serrano, Historia de Guadalajara y sus Mendozas, pp. 167-168.
} 
vos entremetades de prender nyn prendades nyn consitandes prender a los dichos [...] so my guarda e seguro e amparo e defendimiento real [...] por su rey e señor natural ${ }^{86}$.

Lope de Barrientos fue privado regio tras la batalla de Olmedo, cuando el rey pudo elegir a sus verdaderos colaboradores ${ }^{87}$. Los dominicos también fueron importantes embajadores durante este reinado. Entre ellos destacan fray Luis de Valladolid, uno de los embajadores enviados a las negociaciones de Perpiñán en 1415 en representación de Juan II $^{88}$ y en junio de 1423 ante el rey aragonés para explicar la detención de su hermano, el infante Enrique ${ }^{89}$; Juan de Torquemada fue enviado ante el papa en 1449; fray Lope de Galdo, fue embajador del rey castellano en el concilio de Basilea $^{90}$; fray Juan del Corral fue a Inglaterra en 1430 para indicarle a su rey que Juan II quería la paz con él, pese a la alianza sellada con Francia ${ }^{91}$ y al regresar, en 1431 sería el encargado de ofrecer un sermón en Córdoba tras la celebración de una misa y la predicación de una bula de Cruzada emitida por Martín $\mathrm{V}^{92}$. También destaca la actuación de Alfonso de Cusanza en actividades políticas, como el reconocimiento de la infanta heredera Catalina y, posteriormente, de la infanta Leonor, y su participación en el perdón general dado por el rey en $1427^{93}$.

Por lo que respecta a las contiendas bélicas y enfrentamientos en las que se vio inmersa Castilla, los dominicos también desempeñaron un importante papel. Lope de Barrientos, participó en la defensa de la ciudad de Cuenca dirigiendo las tropas concejiles a favor de Juan II y contra Diego Hurtado de Mendoza y sus aliados (14471449) $)^{94}$. Otros dominicos contribuyeron a la pacificación de revueltas internas, como fray Juan de Morales y fray Pedro de Silva. El primero de ellos alcanzó el obispado de Badajoz (1418-1443), teniendo un papel destacado en la pacificación de la nobleza andaluza $^{95}$. Fray Pedro de Silva, por su parte, intervino para sosegar los disturbios provocados en Toledo por el príncipe Enrique contra su padre. Este religioso de San Pedro Mártir de Toledo, era hermano de Juan de Silva, alférez mayor y conde de Cifuentes y según señala Juan López en su crónica de la Orden de los Predicadores

en las alteraciones y movimientos de Toledo del principe don Enrique IV con el rey don Juan su padre, basto el para introducir al rey en el convento una noche y despues

\footnotetext{
${ }^{86}$ CaÑas Gálvez, Colección diplomática de Santo Domingo el Real de Toledo, no 218.

87 Villarroel González, El rey y la Iglesia castellana, p. 153.

${ }^{88}$ Lucía Gómez-Chacón, El monasterio de Santa María la Real de Nieva, p. 155.

89 "E los embaxadores que levaron esta embaxada fueron un maestro en Teología confesor del rey, que se llamaba fray Luis, e un caballero de Toro, que decían Garci Alonso de Olloa", en GALíndez DE CARvaJAL, Crónica del señor rey don Juan Segundo, p. 215.

90 Ibidem, pp. 136-138.

91 Nieto Soria, Iglesia y génesis, pp. 301-302; Galíndez de CARvajal, Crónica del señor rey don Juan Segundo, p. 297.

92 Villarroel González, El rey y la Iglesia castellana, p. 193.

93 Ibidem, pp. 493-494.

94 Díaz Ibáñez, "Iglesia, nobleza y oligarquías urbanas”, p. 232.

95 LuCíA Gómez-CHACón, "Religiosidad femenina y reforma dominicana”, (en prensa).
} 
por su persuasion se redujeron los principales caballeros de aquella ciudad deudos suyos al gobierno del rey y se aparto del servicio de su hijo el principe don Enrique ${ }^{96}$.

Sin embargo, la actuación de los dominicos no siempre estuvo dirigida a apaciguar los ánimos. Así ocurrió con un fraile de la orden, quien en la crónica de Álvaro de Luna se nos muestra como uno de los causantes del asesinato del contador mayor del rey, Alonso Pérez de Vivero a manos del propio condestable en 1453. En un sermón pronunciado por el anónimo predicador en la catedral de Burgos ante Juan II y Álvaro de Luna, el "frayle fabló contra él oponiéndole tantas e tales orribilidades de crímenes, e de maleficios, que sería por çierto cosa muy prolixa averse aquí especificadamente esprimir, escandalizando contra él todos los oyentes". Tras ello, Fernando de Ribadeneyra transmitió al Condestable que el religioso había actuado siguiendo los dictámenes de Alonso Pérez de Vivero, quien fue asesinado poco tiempo después ${ }^{97}$.

Los dominicos también participaron en labores litúrgicas a las que asistió el rey en sus constantes desplazamientos. En el campo de batalla, el soberano se alojó a veces en tiendas, lo suficientemente grandes como para poder reunir a su consejo o escuchar misa; así, en el Real de Almajano, el 27 de julio de 1430, Juan II "fizo juntar todos los de su Consejo en su tienda; e oyo misa el rey, e ellos aparte, la qual misa dixo el obispo de Leon don fray Alfonso, confesor suyo, fraile de Santo Domingo, maestre en Teologia" "98. En octubre de 1445, tras la primera batalla de Olmedo, se llevó a cabo una procesión de acción de gracias en la iglesia de San Esteban de Burgos, siendo un fraile del convento de San Pablo el encargado de dar un discurso al respecto ${ }^{99}$.

Finalmente, tampoco deja de ser curioso que el maestro relojero encargado de construir el reloj de la catedral de Toledo en 1425 fuera fray Pedro de Jaén, profeso en el cenobio dominico de esta última ciudad, lo cual es indicio de la gran labor realizada por los miembros de esta orden en muchos de los campos de la vida sociopolítica de la Castilla del momento ${ }^{100}$.

\subsection{LOS INICIOS DE LA REFORMA DE LA ORDEN DE LOS PREDICADORES (C. 1423-...) Y LAS FUNDACIONES REGIAS}

Pese a que Juan II apoyó los movimientos reformistas surgidos en las diferentes órdenes ${ }^{101}$, fue un fiel colaborador con la reforma de la Orden de los Predicadores, debido a la cercanía a la Corte de muchos de los frailes que impulsaron la misma. Iniciada en Italia por el maestro general de la Orden, Raimundo de Capua en 1380, la reforma no halló eco en Castilla hasta 1423, cuando se produjeron los primeros intentos de reforma de la mano del mencionado fray Álvaro de Córdoba. En dicho año el fraile fundó

${ }^{96}$ López, Tercera parte de la historia general de Sancto Domingo, p. 162. Fray Pedro de Silva también fue embajador del rey castellano en el Concilio de Basilea, en Villarroel GonzÁLEZ, El rey y la Iglesia castellana, p. 103.

97 De Mata y Carriazo (ed.), Crónica de don Álvaro de Luna, pp. 347-350.

98 Cañas Gálvez, El itinerario de la corte de Juan II de Castilla, p. 67.

99 Villarroel GonzÁlez, El rey y la Iglesia castellana, p. 202.

100 PÉrez Álvarez, "La Implantación del reloj mecánico en Castilla”, (en prensa).

101 Villarroel GonzÁlez, El rey y la Iglesia castellana, p. 513-516. 
el convento reformado de Escalaceli ${ }^{102}$ y cuatro años después fue nombrado vicario general de los dominicos por Martín V ante la petición de Juan $\mathrm{II}^{103}$. La actividad reformista de Álvaro de Córdoba fue un fenómeno tolerado por la provincia hispana, que finalmente se circunscribió a la comunidad de Escalaceli, así como al convento de Murcia, fundado por fray Juan de Murcia y unas pocas comunidades más. No fue en las ciudades andaluzas donde se originó la reforma, sino más bien en aquellas cercanas al centro de poder del reino, las castellanas ${ }^{104}$. Dicha reforma no se hace extraña si tenemos en cuenta su contexto. Durante la época del Cisma la Orden se hallaba dividida en tres obediencias, Aviñón, Pisa y Roma, con sus diferentes Maestros o Vicarios Generales ${ }^{105}$. Hacia 1418, tras el Concilio de Constanza, se devolvió la unidad a la orden con el maestro general Leonardo Dati, quien hasta entonces había sido el general de la obediencia romana ${ }^{106}$. La llegada de la observancia a Castilla unos años más tarde que a Portugal se explica por varios factores. Entre ellos destaca que durante los años del Cisma el reino luso prestó obediencia a Roma durante largos periodos, que hasta 1418 la provincia dominica de España englobaba bajo la autoridad de un mismo provincial a cenobios de Castilla y Portugal y que las soberanas de ambos reinos, Catalina y Felipa de Lancaster, eran hermanastras ${ }^{107}$.

El contexto internacional repercutió en Castilla, donde se originó un cisma provincial de la orden durante el provincialato de fray Juan de Santa Justa en 1415; esta situación se mantuvo hasta 1430, cuando se volvió a la normalidad con el provincial fray Juan de Calda. Fueron quince años de tensión y disgregación de las provincias de Portugal y Santiago y reincorporación de Galicia a España y con prioratos provinciales de un año ${ }^{108}$. Todo ello se visualiza en una carta de la reina María de Aragón del 27 de diciembre de 1423, dirigida a las profesas de Santo Domingo el Real de Toledo, Teresa de Ayala y María de Castilla, en que se observa la división de la orden

como agora ha un año, poco mas o menos tiempo, que yo estando en esa çibdat vos estavades so obediencia (roto) del maestro general de la orden de los predicadores et a ynobediençia de fray Luis de Valladolid [...] et agora me es fecha relacion avedes dado vuestra vez al dicho fray Luis e estades a obediencia suya de lo qual yo soy de vos mucho maravillada ${ }^{109}$.

La reforma continuó y otros conventos castellanos abrazaron la misma. Santa María la Real de Nieva se incorporó un poco más tarde, en 1439, cuando en el Capítulo

102 Martínez Casado, Lope de Barrientos, p. 57; Nieva OCAmpo, "Reformatio in membris", p. 300. Sin embargo, unos años antes, el 5 de febrero de 1418, fray Luis de Valladolid obtuvo la licencia de Martín V para la fundación de diez conventos, seis masculinos y cuatro femeninos, como focos de irradiación de la reforma de la Orden de los Predicadores en Castilla, en Lucía Gómez-Chacón, "Religiosidad femenina y reforma dominicana", (en prensa).

${ }^{103}$ Nieto Soria, "El pontificado de Martín V”, p. 129.

104 Nieva OCAMPo, "Dejarlo todo por Dios, es comprar el cielo", p. 485.

105 Hernández, "La reforma dominicana entre los concilios de Constanza y Basilea", p. 5.

106 Nieva OCAMPo, "Reformatio in membris", p. 299; HeRnÁndeZ, "La reforma dominicana entre los concilios de Constanza y Basilea", pp. 10-11.

${ }^{107}$ Lucía Gómez-Chacón, "Religiosidad femenina y reforma dominicana", (en prensa).

${ }^{108}$ Lorente Toledo, San Pedro Mártir el Real, p. 45; Nieto Soria, "El pontificado de Martín V”, p. 129.

109 Cañas Gálvez, Colección diplomática de Santo Domingo el Real de Toledo, nº 162. 
General de la Orden de ese mismo año, el maestro general, Bartolome Texier, ordenó la reforma del convento segoviano; sin embargo, ya en 1432, María de Aragón había tenido en mente reformar el cenobio, como indica en un documento fechado el 8 de agosto: "ya savedes como yo (la reina) mande que los frailes de el monasterio de la dicha villa fuesen en observancia e non pechasen fuera del dicho monasterio" Parece ser que Santo Domingo de Piedrahíta también debió de hacerlo en fecha temprana $^{111}$, algo que no se logró en Salamanca, aunque en 1453 el obispo, cabildo y la universidad denunciaron ante el papa la relajación de los dominicos de San Esteban, exigiendo su reforma ${ }^{112}$. Fray Lope de Barrientos, también comenzó por estos años lo que sería el segundo estadio de reforma de la orden: además de la entrega de San Pedro de Riomoros a la observancia, puso un gran empeño por terminar con el conflicto en las altas instancias de la provincia de España en 1453 y 1454, siendo nombrado el 20 de abril de 1453 visitador de la misma ${ }^{113}$. Por último, no deja de ser significativo que varios de los reformadores más importantes de la época como los frailes Luis de Valladolid, Álvaro de Córdoba y Juan de Torquemada salieran de uno de los cenobios más cercanos a Juan II: San Pablo de Valladolid ${ }^{114}$. Además, al último de ellos se atribuye la reconstrucción de la iglesia de dicho convento, cuyas obras se llevaron a cabo entre 1445 y $1463^{115}$.

El monarca también protagonizó varias fundaciones ayudado por algunos de estos dominicos. En 1434 fundó el convento de Santo Tomás de Aquino de Tordesillas a instancias de fray Luis de Valladolid, escogiendo para ello el día de la festividad del santo titular de la advocación del cenobio ${ }^{116}$. Dicha data coincidía con el cumpleaños del monarca, como señalamos anteriormente, por lo que la obra pía era otra exaltación más de la imagen y poder regio. Pocos años después, Juan II patrocinó el convento de la Peña de Francia, en la sierra salmantina ${ }^{117}$, donde surgieron problemas con el infante Enrique, maestre de Santiago, a quien el monarca había desterrado de Castilla y desheredado y, posteriormente, restituido de todas sus tierras. Alegando el infante que la Peña de Francia estaba en el término de la villa de Granadilla - uno de los lugares devueltos -, se apoderó del convento y tomó su administración intitulándose patrón del mismo. Todo lo anterior movió al rey a conceder en 1445 a los

${ }^{110}$ LuCía Gómez-Chacón, “Reinas y Predicadores: el Monasterio de Santa María la Real de Nieva”, pp. 335-337.

111 En 1448, Fernando Álvarez de Toledo, primer conde de Alba, acrecentó la renta dejada por sus antecesores al monasterio de Santo Domingo de Piedrahíta por haberse pasado a la observancia en 1448, en López, Tercera parte de la historia general de Sancto Domingo, p. 347.

112 Martínez Sopena, "Reforma de los claustros y sociedad", p. 554.

113 Con el respaldo papal fray Lope de Barrientos convocó un capítulo provincial en Toledo al que debería acudir Esteban de Soutello para responder de ciertas acusaciones ante los delegados de todos los conventos. El provincial no se presentó y se le destituyó y sancionó junto a cuantos se oponían a la reforma de la provincia y el nombramiento de fray Pedro de Villaviciosa como nuevo provincial, en MARTínez CASADO, Lope de Barrientos, pp. 57-60.

114 Lucía Gómez-Chacón, El monasterio de Santa María la Real de Nieva, pp. 196 y 202.

115 Ara Gil, "La iglesia de San Pablo de Valladolid", p. 113.

116 Castro Toledo, Colección diplomática de Tordesillas, n 502; Nieva Ocampo, "Los dominicos en Castilla", p. 36; López, Tercera parte de la historia general de Sancto Domingo, Libro Segundo, pp. 109-110.

117 Martínez Casado, Lope de Barrientos, pp. 24-25; López, Tercera parte de la historia general de Sancto Domingo, Libro Segundo, p. 11. Este fue uno de los seis conventos reformados cuya fundación aprobó Martín V en 1418, en Lucía Gómez-Chacón, El monasterio de Santa María la Real de Nieva, p. 151. 
dominicos el privilegio de exención de toda jurisdicción ${ }^{118}$. Con el fallecimiento del infante en Olmedo, Juan II fue en romería al convento y quitó todos los oficiales que aquel había puesto y devolvió la administración a los frailes ${ }^{119}$.

Por otra parte, la conversión del palacio de Miraflores en una casa religiosa tampoco estuvo exenta de las tensiones del momento. La idea originaria del rey era fundar un convento franciscano; sin embargo, no podemos considerar esto como un gesto de acercamiento del monarca a dicha orden, ya que según expresa Juan II en el privilegio fundacional, el motivo principal era satisfacer los deseos incumplidos de su padre y expresados en su testamento de 1406 de fundar un convento franciscano "en enmienda de algunas cosas que el (Enrique III) era tenido de hacer". El testamento de Enrique III señala "otrosi, por quanto prometi de hacer un monasterio de la Orden de San Francisco, en enmienda de algunas cosas que yo era tenido de hacer, mando que los dichos mis testimonios lo hagan"120.

Con todo y con ello, cualquier atisbo de interés que Juan II pudiera tener en vincular el nuevo cenobio a la orden franciscana fue truncado por una serie de intereses contrapuestos. En 1441 la reina María de Aragón negociaba en Burgos con los priores de las cartujas de Scala Dei, El Paular y Las Cuevas la cesión de Aniago a esta última orden, a la que se refiere con las siguientes palabras "considerando que la orden de Cartuxa es muy alta e devota orden e de santa vida"121. En este contexto el rey entregó Miraflores a los cartujos en 1442, seguramente bajo la presión de la reina cercana a los postulados nobiliarios y con la firme oposición del principal valedor y defensor de la autoridad regia: Álvaro de Luna ${ }^{122}$. En una carta enviada por el rey a las ciudades y villas de Castilla tras la muerte del maestre haciéndoles saber las causas de su prisión y muerte, Juan II nos informa de que Álvaro de Luna le persuadía para que no diese limosnas a iglesias ni monasterios "e asimismo turbando y enbargando que yo no edificase ni costruxese la Iglesia y Monesterio de Miraflores, que yo elegí para mi sepultura, ni librasen ni pagasen los maravedís que yo para ello mandé dar" ${ }^{23}$. La oposición del condestable deja entrever el protagonismo de la reina María de Aragón y, quizás del partido aragonés, pudiendo tener dicha decisión connotaciones políticas ${ }^{124}$.

Durante estos años las relaciones entre la orden de la Cartuja y el monarca no parecieron ser buenas: cuando en 1444 el Tostado entró en la cartuja de Scala Dei, Juan II se opuso, le instó a abandonarla y fue nombrado obispo de Ávila ${ }^{125}$. Las dos posturas ante la entrega de Miraflores a los cartujos ¿representan también a la facción monárquica y nobiliaria? Sin poder dar una respuesta segura, lo cierto es que la postura de

118 Pinilla González, El arte de los monasterios y conventos, p. 71.

119 López, Tercera parte de la historia general de Sancto Domingo, Libro Segundo, p. 119-120.

120 Chueca Goitia, Casas reales en monasterios y conventos españoles, p. 99; Sánchez Domingo, Privilegios reales de la cartuja de Miraflores, p. 114.

${ }^{121}$ AHN, Clero secular-regular, Pergaminos, Carp. 3.405, N $\mathrm{N}^{\circ}$. Si bien, no podemos obviar que la primera intención de la reina fue entregarle la casa a los dominicos, quienes lo rechazaron por no ser apto el lugar para su orden, en AHN, Clero secular-regular, Pergaminos, Carp. 3.405, No 10.

122 Arco y Garay, Sepulcros de la Casa Real de Castilla, p. 339; SAlazAr y CaStro, Historia genealógica de la Casa de Lara, III, p. 225; ChueCa Goitia, Casas reales en monasterios y conventos españoles, p. 100.

123 Galíndez de Carvajal, Crónica del señor rey don Juan Segundo, p. 566.

124 Pelaz Florez, "Reynante(s) en vno”, p. 256.

125 Martínez Medina y Martín Biersack, Fray Hernando de Talavera, p. 173. 
la reina María se impuso a la del monarca y su valido. No deja de ser curioso que una vez fallecida María de Aragón, la segunda esposa de Juan II, Isabel de Portugal sellara una carta de hermandad en 1456 con la Orden de los Predicadores, quizás para distanciarse de su antecesora ${ }^{126}$. Curiosamente, en el testamento de la reina María de Aragón

item por quanto yo tengo hermandad con los frayles de Sant Françisco e con los frayles de la horden del Carmen mando que mis testamentarios a mi costa lo fagan saber a cada uno de los generales de cada horden porque ellos enbien mandar a sus monasterios que rrueguen a Dios por mi anima en aquellas cosas que son obligados por yo tener en sus hordenes las dichas hermandades de les mandar alguna limosna ${ }^{127}$

Muchos de estas casas dominicas a las que hemos hecho alusión anteriormente, fueron ampliamente privilegiadas por Juan II al igual que hizo con otros cenobios de la orden. Esto no debe interpretarse como un descuido frente al resto de órdenes religiosas, a las que continuó confirmando privilegios y otorgando otros nuevos; sin embargo, en muchos casos lo hizo como obligación inherente al monarca, teniendo los privilegios dominicos, digámoslo así, un carácter más ligado a su devoción personal.

\subsection{EL PAPEL INTERCESOR DE LOS DOMINICOS TRAS LA MUERTE}

En lo referente a la muerte, varios aspectos relacionan al monarca con la Orden de los Predicadores: la mortaja, el depósito de su cuerpo, el traslado de restos de sus antecesores a conventos dominicos y la fundación de una serie de memorias, aniversarios y capellanías en los mismos. Juan II se sepultó con el hábito dominico - al igual que hizo su mujer, María de Aragón ${ }^{128}-$ y, pese a mandarse enterrar en su fundación de Miraflores, en su testamento ordenó que su cuerpo fuera dejado en depósito en el coro de la iglesia del convento de San Pablo de Valladolid ${ }^{129}$. El 8 de marzo de 1446, Juan II ordenó el traslado de los restos de Pedro I a Santo Domingo el Real de Madrid donde el cargo de priora era ocupado por Constanza de Castilla, nieta del monarca asesinado en Montiel, de quien seguramente partiera la iniciativa. La labor del traslado se encomendó al capellán dominico, fray Pedro de Silva, a pesar de que la noticia que nos ha llegado llame a este fraile Juan, quizás confundiéndolo con su hermano, el conde de Cifuentes, del mismo nombre ${ }^{130}$. Constanza fue designada como patrona

126 Archivo General de Simancas (en adelante AGS), Patronato Real, Leg. 27, doc. 58, citado en PELAZ FLorez, “Reynante(s) en vno”, p. 260.

127 Archivo del Monasterio de Guadalupe (en adelante AMG), LEG. 3, carp. R-VI-4, doc. 15.

128 Idem.

129 RAH, Memorias de Enrique IV de Castilla. Tomo II, $\mathrm{n}^{\circ}$ XLVI; PALEnCIA, Gesta Hispaniensia ex annalibvs, p. 78.

130 “A ocho días de marzo en la tarde año de 1446 en la villa de la Puebla de Alcocer en la Yglesia del señor Santiago Don Gonzalo de Ronda, comendador de Loarte y Zalamea, theniente de don Gonzalo de Sotomaior Maestre de Calatraba, entregó a Juan de Silba un capellán del Rey por uirtud de una cédula real el cuerpo del mui alto señor don Pedro que estaua en un monasterio, de un monumento de un ataúd que estaua guarnecido y cuvierto de un paño de seda de contrani de color de azul brocado de oro de uastones en orma claueteado de clabos menudos de plata sobredorados”, en NogALES RinCón, pp. 1484-1485. 
de la capilla, reservándose el monarca el patronazgo mayor sobre la misma ${ }^{131}$ a la que dotó con 34.000 maravedíes sobre las alcabalas y tercias de la villa de Madrid y su tierra. La capilla fue engrandecida con las donaciones de vestimentas y ornamentos litúrgicos llevadas a cabo por la priora Constanza y por la reina Isabel de Portugal ${ }^{132}$. La priora también fue la artífice del traslado al mismo monasterio de los restos del infante Juan, hijo de Pedro I. Por si fuera poco, en el sepulcro del rey Ordoño II de León (910-914), seguramente renovado en estos años, se representó un monje dominico ${ }^{133}$.

El monarca fundó otra serie de misas, memorias, aniversarios y capellanías en conventos dominicos: el 17 de noviembre de 1419, entregó a San Pablo de Valladolid un juro de 5.000 maravedís con carga de una misa diaria cantada ${ }^{134}$; en su testamento del 8 de julio de 1454 mandó a dicho cenobio sus palacios, casas y huertas que el monarca poseía en un lugar cercano al mismo "porque sean tenudos de faser e cantar e fagan e canten dos aniversarios de cada un año de seis en seis meses por mi anima e de mis defuntos"135. El 16 de diciembre de 1422, Juan II entregó 10.000 maravedís situados en las tercias de la vicaría de la villa de Nieva a la fundación dominica de su madre, Santa María la Real de Nieva, a cambio de otras dos capellanías anuales perpetuas ${ }^{136}$.

\section{EL NUEVO GIRO DEVOCIONAL: EL REINADO DE ENRIQUE IV}

El cambio devocional gestado desde finales del siglo XIV y cuyo culmen tuvo lugar en el reinado de Juan II no tuvo continuidad. Su hijo y sucesor, Enrique IV, se alejó de los dominicos que ahora criticaban la figura del rey. Este fue el caso de Alonso de Burgos, confesor del infante don Alfonso. En 1465, Alfonso, como rey de Castilla, concedió una merced a Diego de Santander y a su hermana Constanza García a petición de "el devoto religioso fray Alonso de Burgos mi confesor". Además, es posible que este fraile participara en la batalla de Olmedo en el bando de don Alfonso. Ambos datos demostrarían la estrecha relación del fraile con la causa de don Alfonso en su enfrentamiento con Enrique IV ${ }^{137}$. Algo similar podemos decir de Juan López de Salamanca, confesor y consejero de Leonor Pimentel, esposa de Álvaro de Estúñi$\mathrm{ga}^{138}$. Este religioso criticó las costumbres arábigas de Enrique IV, a quien también achacaba no haber hecho los esfuerzos posibles en investigar la fe de los conversos. Asimismo hizo una defensa argumental de la deposición de Enrique IV en la Farsa de Ávila, en la que participó el mencionado Álvaro de Estúñiga ${ }^{139}$. En la misma línea, el dominico fray Pedro de Silva, obispo de Badajoz, si había desempeñado una im-

\footnotetext{
131 Romero Fernández-Pacheco, Santo Domingo el Real de Madrid, p. 137.

132 RabadÉ Obradó, "Religiosidad y memoria política”, pp. 235-236.

${ }^{133}$ Nogales Rincón, La representación religiosa de la monarquía castellano-leonesa, p. 811.

134 AHN, Clero, Códices, L. 1261, f. 211.

${ }^{135}$ RAH, Memorias de Enrique IV de Castilla. Tomo II, no XLVI; RAH, Salazar y Castro, O-19, $\mathrm{f}^{\mathrm{0}} 84$ a $84 \mathrm{~g}$.

136 AHN, Códices, L. 925, f. 460 r.

137 Olivares Martínez y Palomo Fernández, "Escudos con flor de lis”, pp. 94-96.

138 Palomo Iglesias, "Libro de Becerro", p. 165.

139 Lora Serrano, "La fundación del monasterio de San Vicente de Plasencia", p. 312; Beceiro Pita, "La nobleza y las órdenes mendicantes en Castilla", p. 352.
} 
portante labor pacificadora durante el reinado de Juan II, no hizo lo mismo en el de Enrique IV, cuando apoyó la causas del infante Alfonso ${ }^{140}$. Es significativo el caso de fray Lope de Barrientos, quien había sido maestro del príncipe Enrique

pero su disciplina se aplicó en vano, pues se entregó tan de lleno desde niño a las obscenidades que el doctor muchas veces confesó públicamente que aquel discípulo había nacido para la ruina del reino y de toda España y para la ignominia de su gente; así que el marqués, receloso de la audacia de varón tan famoso, tuvo cuidado de expulsarlo de la corte inmediatamente después de la entronización de Enrique ${ }^{141}$.

Enrique IV también perdió el apoyo de monasterios clave como Santo Domingo el Real de Toledo, como reflejan los diplomas en favor del mismo expedidos por el infante Alfonso entre julio de 1466 y abril del año siguiente ${ }^{142}$. Ante este panorama no es difícil comprender que los vínculos mantenidos entre la monarquía y la Orden de los Predicadores en los últimos años cayeran ahora en el olvido.

En este contexto, el rey confió y se acercó a otras órdenes como los franciscanos observantes y los jerónimos. En 1455, el rey obtuvo licencia papal para fundar en Segovia a los franciscanos observantes de San Antonio ${ }^{143}$ y volvió a confiar en frailes de esta orden la elección de sus confesores y embajadores. Entre los primeros destacan los frailes Juan del Pino y Alonso de Espina ${ }^{144}$. En cuanto a los embajadores cabe destacar al obispo franciscano de Ciudad Rodrigo, fray Alonso de Palenzuela quien tras la constitución de la liga de nobles en abril de 1460 fue enviado ante el príncipe Carlos de Viana para negociar su matrimonio con la infanta Isabel de Castilla. También acudió como embajador a Roma para dar obediencia a Calixto III (1458-1459) y a Inglaterra para entablar alianza con Eduardo IV (1467) ${ }^{145}$.

Por lo que respecta a la orden jerónima, el rey fundó en 1464 el cenobio de Santa María del Paso en Madrid para conmemorar el sitio donde había tenido lugar el "paso" que mantuvo contra los caballeros enviados por Beltrán de la Cueva. Llevó a cabo el proyecto en agradecimiento a la defensa que este último hizo de la legitimidad de la reina en el torneo, negando su relación con ella y la paternidad de la infanta Juana ${ }^{146}$. Fray Alonso de Oropesa, general de los jerónimos, fue consejero de Enrique IV. Tomó partido frente a la nobleza levantisca que pretendía convertir a los jerónimos en una orden militar. Acudió a las Cortes de Medina del Campo para tratar la revocación del nombramiento de Beltrán de la Cueva como maestre de Santiago y del

140 "El obispo de Badajoz Pedro de Silva tenía como incierto guía de su voluntad a su sobrino fraterno el conde de Cifuentes (partidario de Alfonso), y no podía dar al conde de Feria (Gómez Suárez de Figueroa II); que se consideraba magnate principal de la diócesis de Badajoz, seguro testimonio de cual de los dos partidos prefería", en Palencia, Gesta Hispaniensia ex annalibvs, p. 313.

141 Palencia, Gesta Hispaniensia ex annalibvs, p. 97.

142 Cañas Gálvez, Colección diplomática de Santo Domingo el Real de Toledo, n 257-260.

143 RucQuor, "Los franciscanos en el reino de Castilla", p. 83; GARCía Oro, Los franciscanos en España, p. 81 .

144 García Oro, Los franciscanos en España, p. 78.

145 RAH, Memorias de Enrique IV de Castilla. Tomo II, n ${ }^{\circ}$ CXLIV; Castro y Castro, Crónica de la Provincia franciscana de Santiago, p. 39; Meseguer FERnÁndez, "Memorial múltiple de la Vicaría de Santoyo", p. 487.

146 LADERo QueSADA, "Mecenazgo real y nobiliario”, p. 420. 
juramento de heredera que había hecho el rey a favor de la Beltraneja, concediendo ambas a don Alfonso ${ }^{147}$. Dicha labor del fraile jerónimo la deja clara Enrique IV el 22 de enero de 1465 en la confirmación de un privilegio a San Bartolomé de Lupiana donde fray Alonso de Oropesa era prior -, en el que el monarca expresa

acatando e considerando e los muchos e buenos servicios que el reverendo padre frey Alfonso de Oropesa padre general de la Orden de San Geronimo me ha fecho y faze de cada dia en especial en lo que ha trabajado y trabaja continuamente en la paz y sosiego y tranquilidad de los mis reynos e en el bien de la cosa publica dellos"148.

Por tanto, la intensa relación entre la monarquía y la Orden de los Predicadores que hemos visto durante el reinado de Juan II, pasaron ahora a un segundo plano y, en ocasiones, al más absoluto olvido. Una vez más, el turbulento contexto político y la actuación de las diferentes órdenes religiosas durante estos años llevaron a Enrique IV a decantarse por otras órdenes religiosas.

\section{CONCLUSIONES}

Después de todo lo señalado podemos concluir que las órdenes religiosas sirvieron de elemento de identidad a los monarcas durante la Baja Edad Media. Sin embargo, hubo diferencias, por una parte, entre la dinastía de Borgoña y los Trastámara y, por otra, entre los propios reyes Trastámara. Los primeros monarcas de la nueva dinastía tuvieron actuaciones destacadas hacia los franciscanos, jerónimos y cartujos, intentando crear un proyecto devocional propio, para diferenciarse y separarse de la anterior dinastía y, particularmente de Pedro I. No obstante, pese al franciscanismo latente en las actuaciones de Enrique III, algunos de sus parientes más cercanos serían los que encabezaran el cambio devocional. Su esposa, la reina Catalina, - al igual que demostró su antecesora la reina Beatriz -, y el hermano del monarca, el infante Fernando, hicieron resurgir a la Orden de los Predicadores abandonada por los reyes desde tiempo atrás.

Alcanzada la mayoría de edad por Juan II, los vínculos entre esta orden y la monarquía llegaron a su culmen, apreciándose de una forma nítida desde los comienzos de su vida. Nació en un convento dominico con la ayuda prestada por dueñas de esta misma orden; dominicos fueron los encargados de su educación, desempeñando un importante papel como maestros y ayos; el monarca también se hospedó con frecuencia en las estancias de varios cenobios de la orden, donde también se celebraron importantes ceremonias políticas; en ellos confió aspectos espirituales, como las confesiones, pero también aspectos sociopolíticos como consejeros, oidores de la Audiencia, embajadores, etc.

147 Ibidem, p. 417; Díaz y Díaz, “Alonso de Oropesa”, p. 257; GonzÁLEz Crespo, Elevación de un linaje nobiliario castellano, $\mathrm{n}^{\mathrm{o}} 79$.

148 AHN, Clero secular-regular, Pergaminos, Carp. 578, Nº 18. 
Con la oposición de varios monasterios y frailes dominicos a Enrique IV, éste volvió a confiar en otras órdenes dichos encargos - principalmente, en los franciscanos observantes y jerónimos -, dejando a un segundo plano a los miembros de la Orden de los Predicadores.

Finalmente, conviene también señalar que la primacía de una orden determinada durante un reinado, no implicó el abandono y olvido de las restantes órdenes religiosas por el monarca. Los reyes continuaron favoreciendo y privilegiando a los monasterios y conventos de la Corona pertenecientes a diferentes órdenes. En unos casos por ser el cenobio en cuestión de patronato regio; en otros, pese a ser el centro religioso de patronato nobiliario, los privilegios se deben a otros motivos como la cercanía del linaje protector al monarca o los intentos de este último por atraerse a nobles levantiscos u opositores.

Por tanto, los ejemplos señalados nos muestran un amplio y complejo panorama. Pero no hay lugar a dudas que los cambios devocionales de los diferentes monarcas fueron a su vez el reflejo de la cambiante sociedad política de la Baja Edad Media castellana.

\section{BIBLIOGRAFÍA}

\section{FUENTES DOCUMENTALES}

RAH, Salazar y Castro, N-25, fo 304 a 308.

RAH, Salazar y Castro, O-19, fo 126 a. a $126 \mathrm{f}$.

RAH, Salazar y Castro, O-19, f 84 a 84 g.

AHN, Clero secular-regular, Códices, L. 1261, f. 211.

AHN, Clero secular-regular, Códices, L. 925, f. 460r.

AHN, Clero secular-regular, Códices, L. 1264.

AHN, Clero secular-regular, Pergaminos, Carp. 1.964, nº 3 .

AHN, Clero secular-regular, Pergaminos, Carp. 3.405, No 7 .

AHN, Clero secular-regular, Pergaminos, Carp. 3.405, No 10.

AHN, Clero secular-regular, Legajo 7.562, doc. 3.

AHN, Clero secular-regular, Legajo 7.635.

AGS, Patronato Real, Leg. 27, doc. 58.

AMG, LEG. 3, carp. R-VI-4, doc. 15.

\section{FUENTES BIBLIOGRÁFICAS}

Abad Pérez, Antolín, "Los ministros provinciales de Castilla", Archivo Ibero-Americano, 195-196 (1986), pp. 327-386.

Arco y GaraY, Ricardo del, Sepulcros de la Casa Real de Castilla, Madrid: Instituto Jerónimo Zurita (CSIC), 1954. 
Ara GIL, Clementina, "La iglesia de San Pablo de Valladolid. Aportaciones a un debate”, en Homenaje al profesor Martín González, Valladolid: Universidad de Valladolid, 1995, pp. 113-120.

Ayllón Gutiérrez, Carlos, La Orden de los Predicadores en el sureste de Castilla (las fundaciones medievales de Murcia, Chinchilla y Alcaraz hasta el Concilio de Trento, Albacete: Instituto de Estudios Albacetenses "don Juan Manuel” de la Excma. Diputación de Albacete, 2003.

Ayllón Gutiérrez, Carlos, Iglesia rural y sociedad en la Edad Media (Alcaraz y señorío de Villena), Madrid: Sílex, 2015.

BACKMUND, Norbert, "La Orden premonstratense en España”, Hispania Sacra, 71 (1983), pp. 57-85.

Beceiro PitA, Isabel, "La nobleza y las órdenes mendicantes en Castilla (1350-1530)", en Isabel Beceiro Pita (dir.), Poder, piedad y devoción. Castilla y su entorno. Siglos XII-XV, Madrid: Sílex, 2014, pp. 319-358.

Caballero Escamilla, Sonia, "Palacios y conventos a finales de la Edad Media: la reina Catalina de Lancaster y Santa María la Real de Nieva", Anales de Historia del Arte, 22 (2012), pp. 267-283.

Cantera Montenegro, Santiago, "Las relaciones de las cartujas de la Provincia de Castilla con la monarquía: 1390-1598”, en Concepció Bauçà de Mirabò Gralla (coord.), Prínceps $i$ reis. Promotors de l'orde Cartoixà, Palma: Universitat de les Illes Balears, 2003, pp. 277-292.

Cañas Gálvez, Francisco de Paula, El itinerario de la corte de Juan II de Castilla (14181454), Madrid: Sílex, 2007.

Cañas Gálvez, Francisco de Paula, Colección diplomática de Santo Domingo el Real de Toledo. Documentos Reales I (1249-1473), Madrid: Sílex, 2010.

CAÑas GÁlvez, Francisco de Paula, "Urraca Téllez: Ascendencia social y proyección político-religiosa de una priora de Santo Domingo el Real de Toledo (ca. 1352-1431/32)", Mirabilia. Idealismo ou realidade da mulher na Idade Media, 17 (2013/2), pp. 273-304.

Castillo, Hernando del, Segunda parte de la Historia General de Santo Domingo de su Orden de Predicadores, Valladolid: Impr. Francisco Fernández de Córdova, 1612.

Castro Toledo, Jonás, Colección diplomática de Tordesillas, Valladolid: Institución Cultural Simancas, 1981.

Castro y Castro, Manuel de, Crónica de la Provincia franciscana de Santiago (1214-1614), Madrid: Archivo Ibero Americano, 1971.

Castro y Castro, Manuel de, El Real Monasterio de Santa Clara de Palencia. II Apéndice documental, Palencia: Diputación Provincial de Palencia, 1983.

Cavero Domínguez, Gregoria, "Monarquía y nobleza: su contribución a las fundaciones de clarisas en Castilla y León (siglos XIII-XV)", Archivo Ibero-Americano, 213-214 (1994), pp. 257-280.

Cerro Herranz, María Filomena, Documentación del monasterio de Guadalupe. Siglo XIV, Badajoz: Diputación Provincial de Badajoz, 1987.

Chueca Goitia, Fernando, Casas reales en monasterios y conventos españoles, Bilbao: Xarait, 1982.

Colmenares, Diego de, Historia de la insigne ciudad de Segovia y compendio de las historias de Castilla, Segovia: Academia de historia y arte de San Quirce, 1982. 
Colombás, García María, y Gost, Mateo María, Escritos sobre el primer siglo de San Benito de Valladolid, Montserrat, 1954.

DíAz y DíAz, Luis Alfredo, “Alonso de Oropesa y su obra”, Studia Hieronymiana, Madrid, 1973, pp. 253-313.

DíAz IBÁÑEz, Jorge, "Iglesia, nobleza y oligarquías urbanas", en José Manuel Nieto Soria (dir.), La monarquía como conflicto en la Corona castellano-leonesa (c. 1230-1504), Madrid: Sílex, 2006, pp. 197-252.

Echevarría Arsuaga, Ana, Catalina de Lancaster, reina regente de Castilla (1372-1418), Hondarribia: Nerea, 2002.

Floranes y EnCINAS, Rafael, Memorias para la historia de la ciudad y tierra de Toro, Zamora: Semuret, 1994.

Galíndez de Carvajal, Lorenzo, Crónica del señor rey don Juan Segundo, Valencia: Imprenta de Benito Monfort, 1779.

García Oro, José, Francisco de Asís en la España Medieval, Santiago de Compostela: CSICLiceo Franciscano, 1988.

García Oro, José, Los franciscanos en España. Historia de un itinerario religioso, Santiago de Compostela: El Eco Franciscano, 2006.

GonzÁlez CRespo, Esther, Elevación de un linaje nobiliario castellano en la Baja Edad Media: los Velasco (Tesis Doctoral), Madrid: Universidad Complutense de Madrid, 1981.

GonzÁlez SÁnchez, Santiago, Itinerario de don Fernando regente de Castilla y rey de Aragón (1407-1416), Zaragoza: Fuentes Históricas Aragonesas, 2013.

HeRnández MARTín, Ramón, "La reforma dominicana entre los concilios de Constanza y Basilea”, Archivo Dominicano, 8 (1987), pp. 5-50.

LAdero Quesada, Miguel Ángel, "Mecenazgo real y nobiliario en monasterios españoles: los jerónimos (siglos XV y XVI)", Príncipe de Viana. Homenaje a José María Lacarra, 2-3 (1986), pp. 409-440.

LaYna Serrano, Francisco, Historia de Guadalajara y sus Mendozas en los siglos XV y XVI, Madrid: CSIC, 1942.

Lora Serrano, Gloria, "La fundación del monasterio de San Vicente de Plasencia. La tumba del poder", en Ricardo Córdoba de la Llave, José Luis del Pino García, Margarita Cabrera Sánchez (coords.), Estudios en homenaje al profesor Emilio Cabrera, Córdoba: Universidad de Córdoba, 2015, pp. 307-328.

Llopis Agelán, Enrique, "Milagros, demandas y prosperidad: el monasterio jerónimo de Guadalupe, 1389-1571”, Revista de Historia Económica, 2 (1998), pp. 419-451.

López de Ayala, Pedro, en José Luis Martín (ed.), Crónicas, Barcelona: Planeta, 1991.

LóPEz, Juan, Tercera parte de la historia general de Sancto Domingo y de su Orden de Predicadores, Valladolid: Francisco Fernández de Córdova, 1613, 2 libros.

Lorente Toledo, Luis, San Pedro Mártir el Real, conventual y universitario, Toledo: Universidad de Castilla-La Mancha, 2002.

Lucía Gómez-Chacón, Diana, "Reinas y Predicadores: el Monasterio de Santa María la Real de Nieva en tiempo de Catalina de Lancaster y María de Aragón (1390-1445)", en María Dolores Teijeira Pablos, María Victoria Herráez Ortega, María Concepción Cosmén Alonso (coords.), Reyes y prelados. La creación artística en los reinos de León y Castilla (10501500), Madrid: Sílex, 2014, pp. 325-340. 
Lucía Gómez-Chacón, Diana, El Monasterio de Santa María la Real de Nieva. Arte y reforma dominicana en Castilla en tiempos de Catalina de Lancaster y María de Aragón (13921445), (Tesis Doctoral Inédita), Madrid: Universidad Complutense de Madrid, 2015.

LuCíA Gómez-CHACón, Diana, Apariciones marianas y renovación monástica en la Castilla bajomecdieval: Guadalupe y Santa María la Real de Nieva, Aguilar de Campoo: Fundación Santa $\mathrm{M}^{\mathrm{a}}$ la Real, 2016.

Lucía Gómez-Chacón, Diana, "Religiosidad femenina y reforma dominicana: el sepulcro de Beatriz de Portugal en el Sancti Spiritus de Toro", Anuario de Estudios Medievales, (en prensa).

Martín Prieto, Pablo, "Sobre la promoción regia de la orden franciscana en la Corona de Castilla durante el primer reinado Trastámara", Hispania Sacra, 119 (2007), pp. 51-83.

Martín Prieto, Pablo, "Formación y evolución del patrimonio del monasterio de Santa Clara de Alcocer en la Edad Media", Hispania Sacra, 132 (2013), pp. 563-601.

Martínez CASADo, Ángel, Lope de Barrientos, un intelecutal de la Corte de Juan II, Salamanca: Ed. San Esteban, 1994.

Martínez Medina y Martín BIERsack, Francisco Javier, Fray Hernando de Talavera, primer arzobispo de Granada. Hombre de iglesia, estado y letras, Granada: Universidad de Granada, 2011.

Martínez Ruíz, Enrique, "El monasterio de Santa Clara de Tordesillas. Una aproximación sociológica", en Congreso Internacional de Historia: El Tratado de Tordesillas y su época, Valladolid: Asociación V Centenario del Tratado de Tordesillas, 1995 pp. 1867-1878.

Martínez SopenA, Pascual, "Reforma de los claustros y sociedad en la España de la Baja Edad Media", en Klaus Herbers y Nikolas Jaspert (coord.), Das kommt mir Spanisch vor. Eigenes und Fremdes in den deutsch-spanischen Beziehungen des späten Mittelalters, Münster: Lit Verlag, 2004, pp. 531-564.

Meseguer Fernández, Juan, "Memorial múltiple de la Vicaría de Santoyo, por el P. Rodrigo de Vascones, O.F.M., 1490”, Archivo Ibero-Americano, 76 (1959), pp. 481-490.

Moreta Velayos, Salustiano, "Notas sobre el franciscanismo y el dominicanismo de Sancho IV y María de Molina", en VI Semana de Estudios Medievales de Nájera, Instituto de Estudios Riojanos, 1996, pp. 171-184.

Mata y Carriazo, Juan de (ed.), Crónica de don Álvaro de Luna condestable de Castilla maestre de Santiago, Madrid: Espasa-Calpe, 1940.

Nieto Soria, José Manuel, Iglesia y génesis del estado moderno en Castilla (1369-1480), Madrid: Universidad Complutense de Madrid, 1993.

Nieto Soria, José Manuel, “El pontificado de Martín V y la ampliación de la soberanía real sobre la Iglesia castellana (1417-1431)”, En la España Medieval, 17 (1994), pp. 113-132.

NiEva OCAMPO, Guillermo, "Reformatio in membris: conventualidad y resistencia a la reforma entre los dominicos de Castilla en el siglo XV", En la España Medieval, 32 (2009), pp. 297-341.

Nieva OCAMPo, Guillermo, “'Dejarlo todo por Dios, es comprar el cielo': el voto de pobreza, la mendicidad y el asistencialismo entre los dominicos castellanos (1460-1550)", Hispania Sacra, 124 (2009), pp. 483-512.

Nieva Ocampo, Guillermo, "Los dominicos en Castilla. La génesis de una corporación privilegiada en la Baja Edad Media, en Guillermo Nieva Ocampo, Silvano Benito Moya y 
Andrea Mariana Navarro (coords.), Servir a Dios y servir al Rey: el mundo de los privilegiados en el ámbito hispánico (siglos XIII-XVIII), Salta: Mundo Editorial, 2011, pp. 13-48.

Nogales Rincón, David, “Confesar al rey en la Castilla bajomedieval (1230-1504)”, en Ana Isabel Carrasco Manchado y María del Pilar Rabadé Obradó (coords.), Pecar en la Edad Media, Madrid: Sílex, 2008, pp. 55-80.

Nogales Rincón, David, La representación religiosa de la monarquía castellano-leonesa: la Capilla Real (1252-1504), (Tesis Doctoral Inédita), Madrid: Universidad Complutense de Madrid, 2009.

Olivares Martínez, Diana y Palomo Fernández, Gema, "Escudos con flor de lis o la huella de un prelado promotor: Alonso de burgos, obispo de Cuenca (1482-1485)", Lope de Barrientos. Seminario de Cultura, 6 (2013), pp. 93-124.

Olivera Serrano, César, "Devociones regias y proyectos políticos: los comienzos del monasterio de San Benito el Real de Valladolid (1390-1430)", Anuario de Estudios Medievales, 43, 2 (2013), pp. 799-832.

Palencia, Alfonso de, Gesta Hispaniensia ex annalibvs svorvm diervm collecta, Tomo 1. Libri I-V, en Brian Tate y Jeremy Lawrance (ed.), Madrid: Real Academia de la Historia, 1998.

Palencia, Alfonso de, Gesta Hispaniensia ex annalibvs svorvm diervm collecta, Tomo 2. Libri VI-X, en Brian Tate y Jeremy Lawrance (ed.), Madrid: Real Academia de la Historia, 1999.

Palomares IbáÑEz, Jesús María, “Aspectos de la historia del convento de San Pablo de Valladolid”, Archivum Fratrum Praedicatorum, XLIII, 1973, pp. 91-133.

Palomo Iglesias, Crescencio, "Libro de Becerro del convento de San Vicente Ferrer de Plasencia (I)", Archivo Dominicano, 3, 1982, pp. 165-274.

Pazzis Pi Corrales, Magdalena de, "Santa Clara de Villafrechós, primer monasterio de la congregación de Tordesillas", en Congreso Internacional de Historia: El Tratado de Tordesillas y su época, Valladolid: Asociación V Centenario del Tratado de Tordesillas, 1995, pp. 1879-1894.

Pelaz Flores, Diana, "Reynante(s) en vno”. Poder y representación de la reina en la Corona de Castilla durante el siglo XV, (Tesis Doctoral Inédita), Valladolid: Universidad de Valladolid, 2015.

Pérez Álvarez, Víctor, La implantación del reloj mecánico en Castilla entre los siglos XIV y $X V$, (Tesis Doctoral Inédita), Valladolid: Universidad de Valladolid, 2016.

PÉREZ VIDAL, Mercedes, "Sancti Spiritus de Toro: arquitectura y patronazgo femenino", Liño: Revista anual de historia del arte, 14 (2008), pp. 9-21.

Pinilla GonzÁlez, Jaime, El arte de los monasterios y conventos despoblados de la provincia de Salamanca, Salamanca: Universidad de Salamanca, 1978.

Porras Arboledas, Pedro Antonio, Juan II (1406-1454), Palencia: La Olmeda, 1995.

RABADÉ OBRADÓ, María del Pilar, "Religiosidad y memoria política: las constituciones de la capilla de Pedro I en Santo Domingo el Real de Madrid (1464)", En la España Medieval, 26 (2003), pp. 227-261.

RAH, Memorias de Enrique IV de Castilla. Tomo II, Madrid, 1835-1913.

Revuelta Somalo, Josemaría, Los jerónimos, Guadalajara: Institución Provincial de Cultura "Marqués de Santillana", 1982. 
Rodriguez GuIllén, Santiago, El monasterio de Santa María la Real de Tordesillas (13631509), (Tesis Doctoral Inédita), Alcalá de Henares : Universidad de Alcalá de Henares, 2010.

Rojo Alique, Francisco Javier, "El convento de San Francisco de Valladolid en la Edad Media (h. 1220-1518) (I) Fundación y reforma", Archivo Ibero-Americano, 250-251 (2005), pp. 135-302.

Romero Fernández-Pacheco, Juan Ramón, Santo Domingo el Real de Madrid. Ordenación económica de un señorio conventual durante la Baja Edad Media (1219-1530), Salamanca: Ed. San Esteban, 2008.

RUCQUOI, Adeline, "Valladolid a finales del siglo XV. La ermita de Prado. El monasterio Jerónimo en los siglos XV y XVI", en El monasterio de Nuestra Señora de Prado, Valladolid: Junta de Castilla y León, 1995, pp. 17-66.

RuCQuOI, Adeline, "Los franciscanos en el reino de Castilla", en VI Semana de Estudios Medievales de Estella, Nájera, 1996, pp. 65-86.

RucQouI, Adeline, Valladolid en la Edad Media. El mundo abreviado (1367-1474), Valladolid: Junta de Castilla y León, 1997.

SAlazAr y CASTro, Luis, Historia genealógica de la Casa de Lara, I, Madrid: Imprenta Real, 1696.

Salazar y CASTro, Luis, Historia genealógica de la Casa de Lara, III, Madrid: Imprenta Real, 1697.

Sánchez Domingo, Rafael, Privilegios reales de la cartuja de Miraflores. El patrimonio jurisdiccional de Burgos. Pleito contra el Hospital del Rey, Burgos: Universidad de Burgos, 2004.

Sitges y Grifoll, Juan Blas, Las mujeres del rey don Pedro de Castilla, Madrid: Sucesores de Rivadeneyra, 1910.

SuÁRez Fernández, Luis, Historia del reinado de Juan I de Castilla. Registro Documental (1371-1383), Madrid: Universidad Autónoma de Madrid, 1982.

Villalba Ruíz de Toledo, Francisco Javier, "El monasterio de Santa Clara de Alcocer y su conexión con la monarquía (siglos XIII-XV)”, Wad-al-Hayara, 17 (1989) pp. 319-324.

VIllar y Macías, Manuel, Historia de Salamanca. Libro IV. Desde el señorío de doña Constanza hasta el gobierno de don Alfonso Enríquez, Salamanca: Diputación Provincial de Salamanca, 1974.

Villarroel GonzÁlez, Óscar, El rey y la Iglesia castellana. Relaciones de poder con Juan II (1406-1454), Madrid: Fundación Ramón Areces, 2011.

VV. AA., Diccionario de Historia Eclesiástica de España, Madrid: CSIC, 1972, 5 vols. y suplemento.

YARZA LUACES, Joaquín, La nobleza ante el rey. Los grandes linajes castellanos y el arte en el siglo XV, Madrid: El Viso, 2003. 